\title{
Onorden
}

\section{Human biomonitoring and policy making}

Human biomonitoring as a tool in policy making towards consumer safety

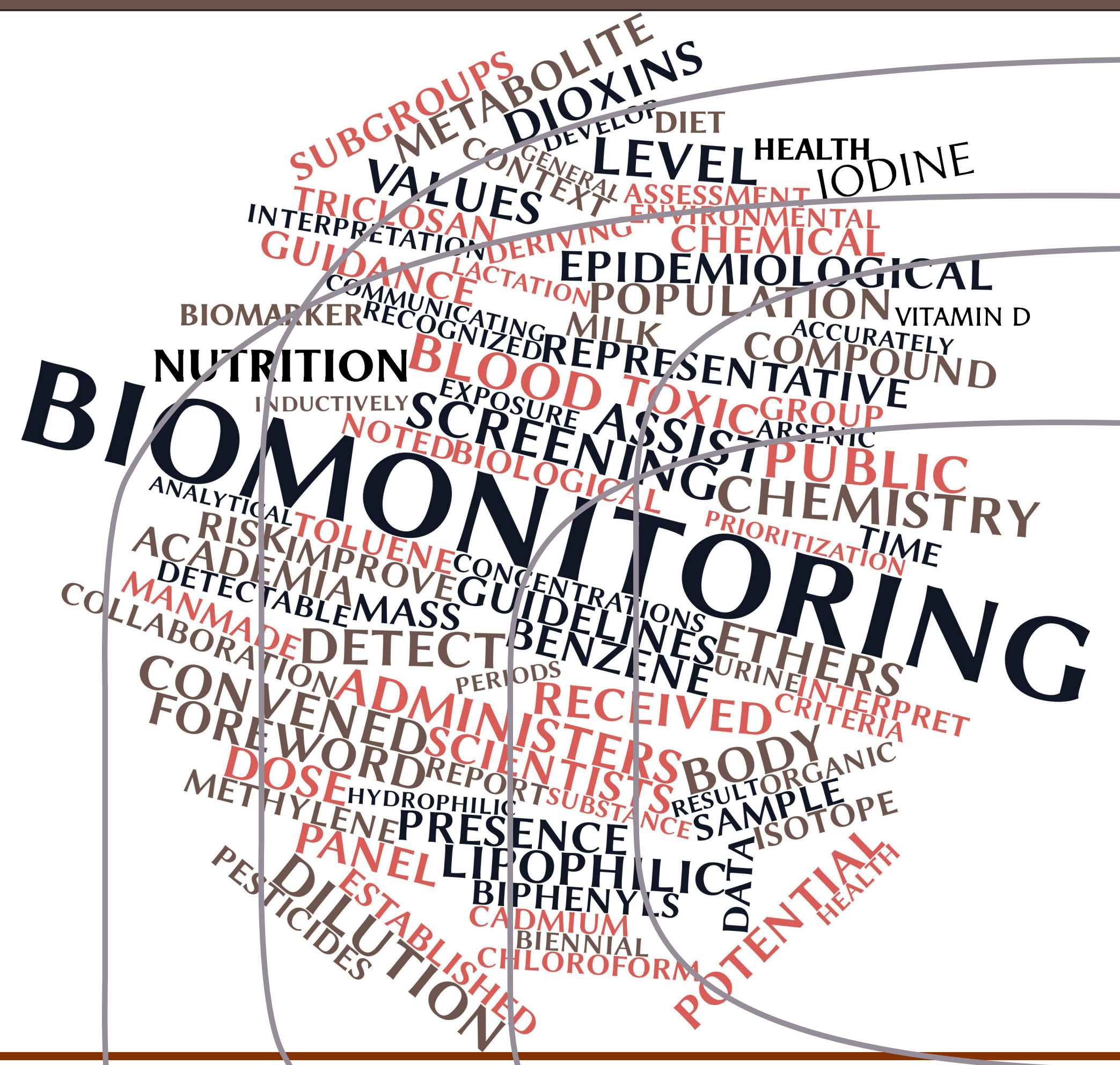



2 norden 



\section{Human biomonitoring and policy making}

Human biomonitoring as a tool in policy making towards consumer safety

Anne Lagerqvist, Bryndís Eva Birgisdóttir, Thorhallur Ingi Halldorsson, Catherine Thomsen, Per Ola Darnerud and Natalia Kotova 
Human biomonitoring and policy making

Human biomonitoring as a tool in policy making towards consumer safety

Anne Lagerqvist, Bryndís Eva Birgisdóttir, Thorhallur Ingi Halldorsson, Catherine Thomsen, Per Ola Darnerud and Natalia Kotova

ISBN 978-92-893-4332-9 (PRINT)

ISBN 978-92-893-4334-3 (PDF)

ISBN 978-92-893-4333-6 (EPUB)

http://dx.doi.org/10.6027/TN2015-571

TemaNord 2015:571

ISSN 0908-6692

(C) Nordic Council of Ministers 2015

Layout: Hanne Lebech

Cover photo: ImageSelect

Print: Rosendahls-Schultz Grafisk

Printed in Denmark

This publication has been published with financial support by the Nordic Council of Ministers. However, the contents of this publication do not necessarily reflect the views, policies or recommendations of the Nordic Council of Ministers.

www.norden.org/nordpub

\section{Nordic co-operation}

Nordic co-operation is one of the world's most extensive forms of regional collaboration, involving Denmark, Finland, Iceland, Norway, Sweden, and the Faroe Islands, Greenland, and Åland.

Nordic co-operation has firm traditions in politics, the economy, and culture. It plays an important role in European and international collaboration, and aims at creating a strong Nordic community in a strong Europe.

Nordic co-operation seeks to safeguard Nordic and regional interests and principles in the global community. Common Nordic values help the region solidify its position as one of the world's most innovative and competitive.

\section{Nordic Council of Ministers}

Ved Stranden 18

DK-1061 Copenhagen K

Phone (+45) 33960200

www.norden.org 


\section{Contents}

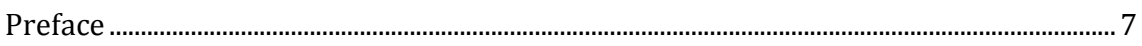

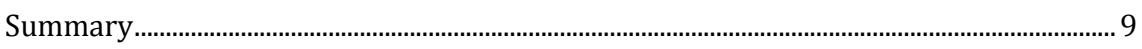

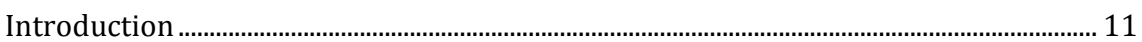

1. Specific seminar topics ......................................................................................................... 13

1.1 50 Years of the U.S. National Health and Nutrition Examination Survey (NHANES).................................................................................................. 13

1.2 The German Human Biomonitoring Commission - Reference- and

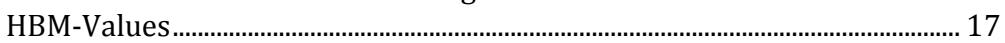

1.3 Comparability of European data in human biomonitoring............................. 22

1.4 Human biomonitoring activities facilitated by the WHO European Centre for Environment and Health................................................................... 26

1.5 Biomonitoring results as support for precautionary policy decisions (Science - Policy - Decisions) ……….............................................. 29

1.6 The Aarhus Birth Cohort Biobank .............................................................................. 34

1.7 Persistent Toxic Substances, environment, climate change and human health effects in the Arctic........................................................................................ 37

1.8 Use of human biomonitoring in risk assessment for food safety ................... 40

2. Debate: From human biomonitoring to regulations - lessons learned...................... 43

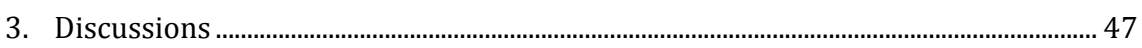

3.1 Reflections from Day 1............................................................................................ 47

3.2 Group discussions ................................................................................................ 51

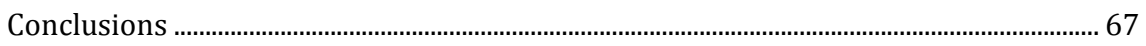

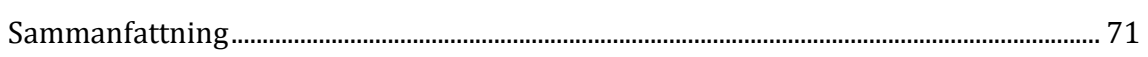

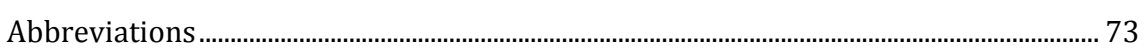

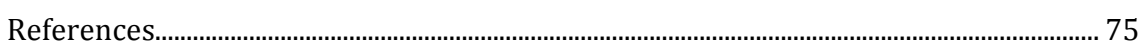

Appendix I: Program.......................................................................................................... 79

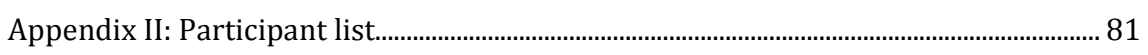





\section{Preface}

Humans are exposed to many different industrial chemicals as well as natural substances and trace elements with toxic potential. The level of awareness concerning the burden of this exposure has recently been raised. This introduces an increasing need to monitor human samples for assessment of exposure to a large number of hazardous compounds, where human biomonitoring (HBM) is a crucial tool. Some of these compounds can exert long-term health effects such as hormonal disruption, impairment of brain development and increased cancer incidence. Pregnant women, fetuses, infants and children are especially vulnerable groups. The need to keep the field of HBM in constant development is therefore crucial, to ensure that it is possible to follow time-trends and have updated information on exposure levels in humans and wildlife. HBM can then be used as a warning system to indicate increasing exposures. Moreover, HBM is considered an essential tool when it comes to assessment of health- and nutritional status. The results from HBM also form a solid platform for decision making and legislation when it comes to risk- and benefit assessment. It also supplies valuable information for the general public about risks coming from chemicals exposure. These advantages are even more powerful if there are strong collaboration efforts between countries and ensurance of harmonization between different studies of the same kind.

The Nordic countries have many factors in common such as similar living standard, culture, diets, climate and exposures from the environment which makes the harmonization easier than between countries which are more culturally and environmentally different. The focus of the seminar "Human biomonitoring as a tool in policy making toward consumer safety" held in Stockholm May 22nd-23rd 2014 was therefore to provide a platform to initiate new and prolong the existing collaboration between the Nordic countries.

Background information was given on different large scale existing projects and general methodological concerns, together with the current threats to human safety from food consumption and other lifestyle parameters. Harmonization and extended collaboration was the focus of discussions which resulted in the conclusion that more of both are needed between the Nordic countries. 



\section{Summary}

This seminar on the topic of "Human biomonitoring as a tool in policy making towards consumer safety" was directed towards professionals involved in human biomonitoring (HBM) programs, legislators and other policy-makers, risk assessors as well as researchers from universities and other higher educational institutions. The seminar was organized by the Swedish National Food Agency (NFA) in collaboration with the Norwegian Food Safety Authority, the Norwegian Institute of Public Health, the Unit for Nutrition Research/University of Iceland, and Karolinska Institute, Sweden. The seminar was held May 22nd-23rd 2014 in Stockholm, Sweden, with financial support from the Nordic Council of Ministers and the Swedish Civil Contingencies Agency (MSB).

Around 60 experts, from Europe, USA and Canada within the field of HBM were present at the meeting. Invited speakers gave presentations on different topics concerning HBM. The participants also engaged in discussions, on different topics related to HBM, which were summarized at a plenary session. The first seminar day was focused on international experiences of HBM as an effective tool for tracing the population's exposure to hazardous substances and assessing nutritional status. Moreover, the potential of HBM as an early warning system for support in policy making to prevent and/or minimize health risks was discussed. The second day was primarily directed towards one of the working groups of the Nordic Council of Ministers - the Nordic Working Group for Diet, Food \& Toxicology (NKMT) - as well as other Nordic partners working with HBM and/or food safety related topics. The overall aim was to actively discuss a basis for Nordic collaboration within biomonitoring of nutrients and contaminants in samples from humans.

It was agreed that HBM provides a powerful tool in policy making towards consumer safety. It was also concluded that there is interest among the attendants to develop the Nordic collaborative efforts within the area of HBM and that there would, unquestionably, be benefits from this in terms of harmonization. 



\section{Introduction}

The Swedish National Food Agency, together with the Norwegian Food Safety Authority, the Norwegian Institute of Public Health, the Unit for Nutrition Research/University of Iceland, and Karolinska Institute, Sweden, organized the seminar "Human biomonitoring as a tool in policy making towards consumer safety." The seminar was held May 22nd23rd 2014 at the Stockholm City Conference Center, Sweden. The seminar had financial support from the Nordic Council of Ministers and the Swedish Civil Contingencies Agency.

Human biomonitoring (HBM) can be used to assess exposure in humans, both at individual and population levels. The contaminants that can be analyzed today include heavy metals which are present in pollution, may occur as natural constituents or can originate from battery producing plants and recycling facilities, natural toxins from plant, fungal or bacterial sources as well as industrially produced chemicals such as flame retardants, surface treatment chemicals, plastic additives or monomers, preservatives, pesticides etc.

One application in HBM is to measure the actual concentration of a contaminant or its metabolite in a biological matrix, so called biomarker of exposure. Other biomarkers are reaction products of a compound within the biological matrix, for example, receptor binding or adducts in DNA or to proteins. Furthermore, an outcome of the aforementioned interaction can be assessed, this is termed biomarker of effect, for example mutations or micronuclei. Human biomarkers can also be directly related to disease outcomes and thus provide basis for legislation for particular contaminants, when they compose a threat to human health. Common practice is to give the biomarker of exposure a guidance value below which the exposure is safe. This is useful in order to interpret exposure levels and to keep the population at tolerable exposure levels. However, there is emerging concern that many compounds or elements, or a mixture of these, might be without such a threshold which makes risk assessment challenging.

Another important factor in HBM studies is measurement of the nutritional and/or health status. This might work as an indicator for a disorder or effects from exposure to toxicants as well as indicate failure to meet dietary needs. The reference value for nutrients is commonly the 
minimal concentration for maintained health with an upper limit to avoid toxicity. The most common method in HBM for nutritional status is measurement of the concentration of the nutrients in human samples, similarly to the biomarker of exposure described above.

The seminar was aimed at determining if there is need and interest for increased Nordic collaboration within the field of HBM. The seminar included presentations and discussions concerning ongoing projects, methods used, parameters analyzed, biobanks and harmonization of HBM. Harmonization was identified as a very important but complex procedure involving other topics and fields. Other aims were: a) to learn from international experiences of HBM as a tool for analysis of nutrients and contaminants, and b) to define the role of HBM as a warning system to take preventive actions in connection to ensuring food safety and regulation.

In total, around 60 participants were present at the meeting. Invited speakers from Europe and USA gave presentations during the first day. On the second day, the participants engaged in discussions, in four groups on different topics. At the end of this day, the discussions were summarized in a plenary session which was used as a basis for establishing the conclusions from the seminar.

Some of the established projects and HBM programs within the field were presented. For example, ongoing Nordic projects and collaboration as well as the EU projects COPHES and DEMOCOPHES which aimed at developing standardized protocols for HBM in Europe and testing them in a first EU wide pilot study, were highlighted. The National Health and Nutrition Examination Survey (NHANES), an US national program for health assessment within which a wide range of environmental pollutants are regularly measured in human samples, was also presented. Furthermore, the establishment of the German HBM-Commission was outlined and the aim to aid in data interpretation and to make recommendations concerning exposures to individuals as well as the general population was explained. Another mentioned effort within the field was the WHO project which provides descriptions for standardized HBM methodology based on broadly accepted methods in collaboration with the EU.

The specific topics of the seminar are summarized below followed by a compilation of the essence from the discussion sessions as well as the conclusions derived from the seminar. The seminar program and participant list can be found in Appendix 1 and 2 respectively. 


\title{
1. Specific seminar topics
}

\author{
1.1 50 Years of the U.S. National Health and \\ Nutrition Examination Survey (NHANES)
}

Dr. Antonia M. Calafat, Chief of the Organic Analytical Toxicology Branch, Division of Laboratory Sciences, National Center for Environmental Health (NCEH) of the Centers for Disease Control and Prevention (CDC), Atlanta, GA, USA.

\subsubsection{General information about NHANES}

The National Health and Nutrition Examination Survey (NHANES) is a US national program for health assessment as well as monitoring of nutritional status and exposure to contaminants in the general population [1]. NHANES originated in 1956 with the National Health Survey Act that established a national health survey to obtain information on the health status of US residents, and has widened considerably since then [2]. Since 1999 NHANES is an annual, cross sectional survey focused on obtaining clinical, nutritional and other HBM data representative of the general population for prevention of disease. The data are available for public access, and have been used in a vast number of scientific publications [3].

Within NHANES, a wide range of environmental pollutants and nutrients is measured in human samples at the Centers for Disease Control and Prevention (CDC) [4]. CDC's National Reports on Human Exposure to Environmental Chemicals are available online together with reports on biochemical indicators of diet and nutrition [5]. Public health institutions use the reports in various ways, such as determination of prevalence of disease connected to specific exposure(s) in humans.

NHANES HBM data can also be used in policy making.

\subsubsection{Sampling cycles, data collection and use}

The data are collected in two-year cycles and around 10,000 people are examined within each cycle both clinically and/or for biomarkers (of exposure). The examination takes place in a mobile examination center [6]. There are three categories of collected information: health examina- 
tion (e.g. physical examination), questionnaires (e.g. medical history, diet, demographic, socioeconomic and behavioral data) and laboratory analyses $[7,8]$. In most cases, HBM is conducted in a subset of the population. Individuals of all ages are included in NHANES but the amount of urine or blood collected for HBM differs between children and adults. Small children (1-5 years) give small blood volumes and no urine. From 6 years of age, urine and blood samples are collected, but the blood amounts are too small for extensive HBM analyses. Except for cotinine and selected metals, blood measurements of other chemicals are available only among persons 12 years of age and older. At present, approximately 250 environmental contaminants are monitored amongst which are metals, organic contaminants, persistent organic pollutants (POPs), non-persistent contaminants and emerging contaminants [5]. Nutritional status is also evaluated through measurement of vitamin status, trace elements and other components [9].

The NHANES data can be used to investigate prevalence of disease and to promote strategies on how to improve public health and prevent disease. NHANES data can assist in risk assessments and can be used as a guide, based on prevalence, to establish reference levels. NHANES data can indicate widespread exposure, and thereby provide suggestions for specific chemicals or chemical classes that are important to focus on. The CDC's National Reports contain limited data interpretation and no health outcome analysis, but they provide data to be used by researchers and other stakeholders.

NHANES participants get a report of the findings, but not for all chemicals tested, only for lead, cadmium and mercury [10]. Based on the NHANES 2012 data, lead reference levels were lowered to $5 \mu \mathrm{g} / \mathrm{dL}$ blood (this value was based on the $2,5 \%$ of children which have the highest levels) [11]. No safe level of lead exposure exists and it is important to prevent lead exposure before it occurs.

A summary of the procedure for selection of chemicals to be measured within the program can be found on the CDC website [12].

\subsubsection{Examples of life style related exposures}

Antibacterial compounds: The higher the household income, the more triclosan is present in the urine of NHANES participants [13, 14]. Antibacterial products may not be needed in every household, but are needed in hospital and other clinical environments. NHANES data were used in the 2008 US EPA human health risk assessment of triclosan. 
Parabens are present at much higher levels in women than in men probably due to the use of personal care products containing these compounds [15].

Benzophenone-3 which is used in many sunscreens is measured at lower concentrations in older children compared to younger ones, and at higher concentrations among non-hispanic whites than other race groups [16].

Cotinine measurements, an indicator of exposure to cigarette smoke, showed a decrease in the non-smoking population when smoking bans were enforced [17]. Cotinine is still detectable in small children perhaps because indoor smoking became more frequent when smoking bans were enforced in public places.

Perfluorooctane sulfonate (PFOS) was measured for the first time in NHANES in 1999-2000. PFOS is no longer produced in the US and the measured concentration in the population_has decreased considerably (down 68\% since 1999) [5, 18]. However, this compound is still produced in China and since it is distributed in the atmosphere and biota levels in people might increase in the future [19].

Regarding phthalates, regulatory actions have taken place in EU earlier than in US [5]. The level of the dibutyl phthalate (DBP) metabolite, monobutyl phthalate (MBP) has gone down in the US population [20]. MBP has shown adverse health effects in animals. Instead, the urinary levels of the diisobutyl phthalate (DiBP) metabolite, monoisobutyl phthalate (MiBP), appear to be increasing in the population. However, less is known about the health effects of this substitute. The exposure to diethyl phthalate (DEP), which is used as a component in fragrance, is decreasing probably since the population tends to choose non-perfumed products. In contrast, individuals medicating with a colitis drug (mesalamine) containing DBP in the pill, have extreme levels in comparison to non-users [21]. Due to this, there is cause for concern, especially for pregnant women, because concentrations in certain individuals come close to those which show effects in animal tests. Thus, pregnant women might be advised to use an alternative drug without DBP since it is not needed for the pharmaceutical effect but is an inactive ingredient. This is an example of how HBM data collected through NHANES can identify high exposures in a subset of the population.

In products for children, a number of phthalates are regulated in the US, as well as in the European chemicals legislation (Registration, Evaluation, Authorization and restriction of Chemicals REACH) [22]. Nonetheless, because of consumer demands, phthalate-free products are now commercially available. 


\subsubsection{Conclusions}

NHANES provides continuous data on exposure to environmental chemicals and nutritional status. Obviously, research benefits from the availability of such continued national surveys. The HBM data can be linked to health outcomes as well as sources of exposures, but they cannot answer all public health issues. One limitation of NHANES is the cross sectional design which does not allow for linkage of exposure with health outcomes over time as it would in a prospective cohort study.

Additional studies involving vulnerable and susceptible populations, as well as studies of highly exposed populations, would provide useful data for these groups not specifically targeted in NHANES. More information about NHANES is available at the CDC website [23].

\section{Questions}

1. If high phthalate levels in some individuals are identified, can those participants be informed?

No. The only HBM data reported to the participants are the levels of lead, cadmium and mercury.

\section{How are the samples kept? Is there a biobank?}

The samples are collected and stored in a central repository at or below $-70^{\circ} \mathrm{C}$. Residual samples of plasma, whole blood and urine which are left after the intended measurements can be used for research. Nonetheless, in most publications related to NHANES, investigators use the already available data.

3. If there is a large group of children with high levels of lead found, what is done?

There is an alert system for lead which involves informing the physician and persons concerned. Lead is analyzed rapidly and the results are given to all participants. Information to the public about lead levels in children is published on the CDC website [11].

4. Can you go back and look at the health of certain individuals if, for example, finding a high concentration of a chemical in a specific sample? No, not for specific persons, but you can relate the HBM results to the other health parameters based on non-identifiable sample-IDs. 


\section{How are the participants recruited?}

Participants are selected through a complex statistical process using the most current Census information. Recruitment for participation in NHANES is based on age, sex and ethnicity.

6. Are prospective analyses of mortality performed?

Not as part of the design of NHANES. However, NHANES data are publicly available and there are peer-reviewed publications examining associations between data collected for NHANES and mortality.

7. Do the participants give consent to their participation?

Yes, for the analyses performed and for future research. They can choose not to consent that their specimens are used for future research (it does occur).

8. Do you analyze some biomarkers of effect?

No. At present, at CDC we only measure biomarkers of exposure. However, new aspects are evaluated continuously which might make analysis of biomarkers of effect possible in the future.

\subsection{The German Human Biomonitoring Commission - Reference- and HBM-Values}

Dr. Marike Kolossa-Gehring, Dept. of Environmental Hygiene, Section Toxicology, Health Related Environmental Monitoring / Umweltbundesamt (Federal Environment Agency / UBA), Germany.

\subsubsection{Cause for concern}

The need of biomonitoring was presented through historical examples concerning lead. Close to battery production plants, children and animals were exposed to high amounts of lead. Furthermore, high levels of lead have been found in blood samples from children living near smelting plants. Such unfortunate events showed that there was need for a joint action to avoid and assess exposures in the population. These realizations lead to the establishment of a German HBM system on the federal level consisting of the Environmental Specimen Bank (ESB) and the population representative German Environmental Survey (GerES) as well as to founding of the German Human Biomonitoring Commission. The data mainly generated in GerES are used to derive reference- and 
HBM-values which can be used as a tool to judge the overall exposure or one measured for a certain reason. The Reference value (RV95), for a chemical substance in human biological material (e.g. blood, urine), is a value which is derived according to a defined statistical method from a series of measuring results obtained for a sample of a defined group of the general population. HBM-values, by contrast, are derived on the basis of toxicological studies and are based on expert judgment. The HBMvalues allow health assessment of pollutant levels found in human samples. The task of deriving reference- and HBM-values is fulfilled by a special expert commission counselling the Federal Environmental Agency. Up to now, this Commission has derived HBM-values for a number of chemicals, mainly for adults. Details can be found at http:// www.umweltbundesamt.de/en/topics/health/commissions-workinggroups/human-biomonitoring-commission/reference-hbm-values.

\subsubsection{The Human Biomonitoring Commission}

The Human Biomonitoring Commission (HBM-Commission) was initiated in 1992. It is aimed to aid in data interpretation by statistical derivation of reference values and toxicological-epidemiological derivation of HBM-values I and II (see below). Additionally, the HBM-Commission was asked to make recommendations concerning chemical exposures to the public health services, individuals, the general population and policy makers [24]. Recommendations of this kind are needed to ensure well maintained health status of the population, to control the success of chemicals policy and to further develop it. Publications with results from the HBM-Commission are present online [25].

The main focus of the HBM commission is to provide:

- Reference values.

- Human Biomonitoring values (HBM-I and HBM-II)

- HBM Monographs.

- Supervise the planning and use of the data from the population representative German Environmental Surveys (GerES) and the Environmental Specimen Bank (ESB).

- Give advice on the reliability of analytical methods.

- Set quality assurance standards. 


\subsubsection{Reference- and HBM-values}

The reference value (RV95) represents a background level of the exposure of defined sub-groups. The statistically derived reference values are based on the levels in a reference population at the 95th percentile. To derive them, preferably population representative exposure data, reliable analytical methods and an extended quality assurance system are needed. Differences in exposure can exist between individuals for several reasons. One such example is the presence or absence of amalgam dental fillings which contain mercury. Reference values have to be derived for reference populations and can differ for age groups, gender or individuals with specific habits (for example smokers, fish consumers etc.)

Upon decision, the reference values are announced on the UBA webpage of the HBM-Commission. About 50 reference values have been developed so far. The reference values are in constant development, e.g. the RV95 for mercury which has decreased notably from 1992 to 2005. Currently, no up-to-date reference values for lead in blood are available since they need to be re-derived (and presumably lowered) on the basis of up-to-date HBM data. For some other contaminants, deriving RV95 is challenging. For example, PCBs in blood vary with age and level of fish consumption. For assessment of such compounds, environmental surveys and demographic information are needed in addition to HBM for deriving appropriate reference values.

For the HBM-values two levels are defined: HBM-I and HBM-II. The HBM-I-value reflects the concentration below which there is no health risk. At a concentration between HBM-I- and HBM-II-values, the result should be verified by further measurements. The HBM-I-value can be interpreted as a control value. The HBM-II-value represents the concentration of a substance in a human biological material above which there is an increased risk for adverse health effects. Exceedance of the HBM-IIvalue should therefore be further evaluated by experts in environmental medicine or, if required, medical treatment, and should be followed by measures to eliminate potential sources of exposure. The HBM-II-value therefore represents an intervention level. When deriving HBM-values, it is crucial to know that there is a difference in sensitivity between children and adults.

No safe level for genotoxic carcinogens can be defined. How to address this issue is still under discussion and currently no HBM I value can be assigned for these compounds. In general, when determining the HBMvalues, in the beginning solely epidemiological data were used as a basis. Later on, tolerable daily intake (TDI), No Observed Adverse Effect Level (NOAEL) or Bench Mark Dose (BMD) in combination with certain assess- 
ment factors (AF) were and are used. This approach is based on the new position paper from the HBM-commission published in 2013 [26].

\subsubsection{Human Biomonitoring methods}

Specific standardized methods used for HBM within the program of the HBM Commission can be found in "Biomonitoring methods" (the fourth part within the MAK collection published by Wiley - VCH, containing 150 methods covering about 350 chemicals) [27, 28]. The HBM-Commission also publishes monographs on chemicals relevant for HBM, including information on use, occurrence, sources, uptake, distribution, excretion, toxic effects and determination of internal exposure. Furthermore, the monographs include analytical methods, reference values, HBM-values, relevance in environmental medicine, appropriate measures and current scientific references.

\subsubsection{The responsibility of the chemical industry and problem inherit in substitution}

There are increasing requirements on HBM to meet the needs for investigation of exposures to emerging compounds as well as assessment of combined effects. Therefore, the German Federal Ministry for the Environment, Nature Conservation, Building and Nuclear Safety (BMUB) and the German Chemical Industry Association e. V. (VCI) started their cooperation to increase the knowledge on the internal exposure to chemicals of the general population in 2010. The Federal Environment Agency plays a vital role in this cooperation. Emphasis is placed on substances with either potential health relevance or on substances to which the general population might potentially be exposed to a considerable extent. Substances of interest are identified by a scientific advisory panel in cooperation with the Federal Scientific Agencies in charge of chemical regulation and VCI. New HBM methods for the sensitizing agent methylenediphenyl diisocyanate (MDI), and the two plasticisers Hexamoll ${ }^{\circledR}$ DINCH, Di-2-propylheptyl phthalate (DPHP) used as substitutes for DEHP (Di-2-ethylhexyl phthalate), have been developed as part of the VCI tasks. These methods have to be additionally validated by the HBM working group of the German Research Foundation and published in international peer reviewed journals. UBA started to derive toxicologically based guidance values (HBM-I-values) for the first 5 chemicals and investigation of time trends for the DEHP substitutes. The new methods will be applied to samples of the non-occupationally exposed general population. The pilot phase of the 
project proved that cooperation between the public sector and industry on the basis of separate responsibilities is effective to extend knowledge on the present exposure of the population to chemicals. Identification of an appropriate marker is a prerequisite for method development even if preliminary HBM data have been published. Non-invasive sampling increases the applicability in population studies. This project will contribute to a realistic estimation of human exposure to relevant chemicals in the German population. The data will be used for risk assessment on the chemicals of interest. With information from the industry, additional knowledge on chemicals properties will be accessible, thus contributing to the development of a HBM-value.

The problems of substitution can be exemplified by the plasticizer DEHP being substituted by Diisononyl cyclohexane (DINCH). DINCH is according to current knowledge less toxic than DEHP. However, for a risk assessment, the current exposure levels have to be evaluated in a population representative sample. German children are still exposed to critical levels of DEHP while effects have not been found for DINCH yet. The HBM-I-value for DINCH is more than one order of magnitude higher than the highest value found so far. In Germany, $1.7 \%$ of the population has levels above the HBM-I for DEHP, although mean exposure levels are lower than the EU mean. The other DEHP substitute Dipropylheptyl phthalate (DPHP) is less toxic than DEHP. The respective HBM-I-value was derived based on effects on the thyroid and pituitary gland.

\subsubsection{Conclusions}

Based on environmental surveys, reliable analytical methods, quality assurance, and dose-response relationships, the HBM-Commission evaluates reference values and HBM values. By this way, the HBMCommission enables the use of HBM for exposure assessment, risk assessment, and risk management. The Reference values of the HBMCommission are highly accepted benchmarks which are useful not only in Germany. However, we need more HBM values to give guidance if a substitute for a toxic chemical is the better alternative, if consumers should be concerned about potential exposure from use of chemicals/products, or if the measures taken under REACH are good or not.

New monographs and HBM values are continuously produced by the HBM-Commission which is obligated to determine up to 50 new HBM values until 2020 (BMUB/VCI co-operation chemicals, GerES V). Perfluorinated compounds comprise one such group which is currently in focus for determination of HBM- and reference values. Other new chal- 
lenges are to evaluate cumulative HBM for all phthalates as well as biomarkers of effect. International collaborations could increase the number of available results from analyses and aid in harmonization.

More information is available at the webpage of the HBMCommission which is appointed every three years by the president of the German Federal Environment Agency (Umweltbundesamt) [29, 30].

\section{Questions}

1. Is more HBM needed to evaluate substitution problems and are REACH measures good enough?

More collaboration is ongoing and needed, ex. Toxicology Summit. The REACH lists do not cover enough compounds yet.

2. There are problems of setting HBM values for carcinogens/genotoxins. How is this related to the mode of exposure?

The clear statement from the HBM-Commission is that exposure of the general population to carcinogenic/genotoxic compounds has to be minimized. The HBM-Commission is currently discussing how far to go, i.e. what limits to put in Germany.

3. What is done regarding endocrine disrupting chemicals (EDCs)?

Some EDCs are included in the program and have thresholds but there is a challenge concerning mixture exposures and combined effects. The commission is currently developing a total HBM value for the five phthalates investigated in GerES and ESB.

\subsection{Comparability of European data in human bio- monitoring}

Prof. Milena Horvat, Head of the Dept of Environmental Sciences, Jožef Stefan Institute, Ljubljana, Slovenia.

\subsubsection{The complexity of comparability and the importance of data quality and standardization}

The comparability between measurements is not the only issue to address. Other factors, such as sampling procedure, handling and storage need to be taken into consideration. 
What are data quality objects (DQO)? The DQO need to be identified and standards set for the different parameters at the initiation of the study:

- Clarify the study objective.

- Define the most appropriate type of data to collect.

- Determine the most appropriate conditions from which to collect the data.

- Specify tolerable limits on decision errors which will be used as the basis for establishing the quantity and quality of data needed to support the decision.

In addition, there are many questions to address at startup, some of which are:

- Are there existing problems between single or multiple labs used for analysis?

- Is food or environmental samples being analyzed?

- What is doable in the real world?

- What would be ideal?

These types of questions need to be addressed thoroughly before the start of the study since the HBM studies are complex and costly. HBM includes not only collection and analysis. Proper statistical analysis is also important to ensure that the study will be feasible and have high standard.

Two European twin projects have been conducted - Consortium to Perform Human Biomonitoring on a European Scale (COPHES) and DEMOnstration of a study to Coordinate and Perform Human biomonitoring on an European Scale (DEMOCOPHES) [31, 32]. The aim within these two projects was to develop standardized protocols for HBM in Europe [33].

An example of specifics for standardization is measurement of organic and inorganic mercury in human subjects. For example, in the Mediterranean countries the human mercury levels are higher since large consumption of fish gives increased levels in human blood. Within DEMOCOPHES, mercury in hair was measured and it was found that parts of the European population exceed the tolerated level $(0,58 \mu \mathrm{g} / \mathrm{g}$ hair). The amount of the population exceeding the levels differ between the 17 participating European countries with some exhibiting levels 
higher than $0,58 \mu \mathrm{g} / \mathrm{g}$ hair in over $50 \%$ of the population while others are at less than $5 \%$ exceeding the tolerated level. There are also some hotspots in soil for mercury which might add to the elevated levels in some populations. This and other different ways of mercury exposure (as compared to high fish consumption) are often neglected and need further assessment. This is done in an EU funded project called The Global Mercury Observation System (GMOS) [34]. It is a five year project (2010-2015) involving more than twenty institutions from Europe, North and South America, Asia and Africa. GMOS aims to chart mercury contamination throughout the globe in different matrices. This global observational system puts all data, from different sources, into a common database with a large combination of matrices, emissions, marine biota etc. Harmonized quality of the data is important here since it will be present in a common system.

HBM can also be put in the context of integrated assessments of many different parameters since all compartments taken into account are highly complex and important parameters for providing the whole context. This type of analysis involves different matrices such as aquatic biota, humans and wildlife, air, water, sediment as well as data from intensive sites and different regions.

\subsubsection{Centralization versus decentralization of analyses}

Is it better to centralize the analyses in one lab or use multiple labs? One example given showed enormous deviation between the laboratories. Even if the curves presented had the same shape, the total concentration differed enormously. It takes a lot of effort to standardize a method between labs and the risk of having the wrong values is obviously large. For cadmium the measured difference was almost $100 \%$ between two labs using parts of the same sample.

Public Health Impact of long-term low-level Mixed Element Exposure in susceptible population strata (PHIME) was an EU project which addressed HBM of mercury, lead and cadmium in human blood samples and inter-comparison between laboratories [35]. There was a vast discrepancy between labs when analyzing those metals. This affects the size of the number of participants needed in studies. Power analyses revealed a need for a large number of participants to detect differences, when discrepancies between the analyzing laboratories exist. The conclusion was that only one lab should be used for analyses.

Moreover, when including children, not enough sample volume can be collected to compare results from different laboratories. It is there- 
fore better to improve the measurements than to have more individuals to account for analytical or statistical problems.

To choose one lab for all analyses is obvious to get reliable data which could be compared between different samplings and measurements. This was addressed in a publication in 2012 within the COPHES and DEMOCOPHES projects mentioned above [36]. Furthermore, specialized capacity needs to be built for measurements of low concentrations. Only 3 out of 40 labs could do this satisfactory within a year; it takes large amounts of time and effort to set up and standardize a method.

\subsubsection{The science of metrology - appropriate measure- ments and comparability}

Metrology is the science of measurements with the paradigm being: Sampling - Processing - Measurement - Result. Parameters which need to be taken into account are:

- Concerning sampling

- representativity

- appropriateness

- sources of possible contamination

- stability and handling of the samples.

- Concerning processing

- Dissolution

- extraction and dilution practices.

- Concerning measurements

- conversion to SI units or conventional scale.

- Concerning results

- a certain amount of uncertainty will always be present but this should be minimized.

What are the basic requirements for appropriate measurement to monitor exposure changes in time and space? Firstly, analytical measurements need to be comparable in time and space. Secondly, there are uncertainties in each step concerning comparability. Traceability is therefore of crucial importance. Adding to this, standards for calibration are needed. The fact that different reference materials give different concentrations in the unknown sample also has to be taken into account. The right reference material should therefore not have large uncertainties. Since lots of resources are spent and there are also ethical implications, the need for accurate data production is of utmost importance. 


\subsubsection{Conclusions}

HBM requires production of accurate data in time and space in order to achieve comparability. It is better to improve the measurements than to have more individuals to account for analytical or statistical problems. One problem is that current reference materials are insufficient. Further on, multicenter studies reveal that when comparing single versus multiple laboratory studies, the ones using a single laboratory are preferred beyond doubt. Therefore, the conclusion is that only one lab should be used for analyses. Hierarchical metrology structures and technical infrastructure need to be developed in practice for successful HBM. Support for this is needed both at regional and global level.

\subsection{Human biomonitoring activities facilitated by the WHO European Centre for Environment and Health}

Dr. Andrey Egorov, Environmental Health Information System (ENHIS), World Health Organization. Bonn, Germany.

\subsubsection{Development of standardized HBM methodology for monitoring the implementation of Parma Declara- tion commitments}

The World Health Organization's (WHO) European Region includes 53 Member States with 880 million people. WHO Regional Office for Europe coordinates the European Environment and Health Process, which involves regular ministerial conferences on environment and health. The 5th conference (Parma, Italy, 2010) adopted commitments to act to protect children's health including a specific target to protect children from harmful substances focusing on pregnant and breast-feeding women and to develop a consistent and rational approach to HBM as a complementary tool to assist evidence-based measures [37]. The WHO European Centre for Environment and Health (ECEH) in Bonn, Germany, has coordinated the development of a standardized methodology for cross-sectional HBM surveys in maternities based on broadly accepted methods, such as those which were used in the COPHES/DEMOCOPHES projects [38]. This approach aims at countries which currently do not have national HBM programs and volunteer to use the WHO methodology in the framework of monitoring the implementation of Parma commitments [39]. The current version of the WHO methodology includes a framework survey protocol 
and questionnaires as well as standard operating procedures (SOPs) for sampling, laboratory analysis and statistical analysis of data. The survey includes only non-invasive sampling and involves the following biomarkers: mercury in maternal hair, maternal urine and cord blood, cadmium in maternal urine, arsenic in maternal urine and lead in cord blood. It is recommended to conduct national surveys in a set of randomly selected maternity clinics to characterize exposures in the general population and in maternity clinics serving contaminated areas or heavily exposed populations (the high exposure arm of the survey focusing on priority pollutants to be identified in each country).

Other priority biomarkers which were identified through WHO technical meetings include urinary cotinine, POPs (except dioxin-like substances) in cord blood, urinary biomarkers of exposure to polycyclic aromatic hydrocarbons (PAHs) and benzene, toluene, ethylbenzene, and xylenes (BTEX), phthalates and non-persistent pesticides. SOPs for these biomarkers can be incorporated in national survey protocols depending on existing data on exposures.

The first pilot survey using the standard WHO methodology was conducted in 2013 in the Moscow Region of the Russian Federation. The survey involved five randomly selected maternity clinics and one maternity clinic serving an industrially contaminated area with high levels of lead and arsenic in soils. According to the protocol, 20 women were recruited in each maternity clinic for a total of 120 women. Mercury in hair and cord blood as well as blood lead levels were relatively low compared to other European countries. All measurements of lead were below $5 \mu \mathrm{g} / \mathrm{dL}$. The low level of lead, while expected in the general population, was surprising for the contaminated area. While geometric mean cadmium level was similar to the level in the US based on the NHANES results, the total arsenic level was substantially higher. There was a strong association between the consumption of bottled mineral water and urinary arsenic level, which warrants further investigation to identify brands of contaminated bottled water.

\subsubsection{The joint project to develop a scheme for global monitoring of mercury under the Minamata conven- tion involving the United Nations Environment Pro- gram (UNEP) and_WHO}

The Minamata convention is a legally binding instrument aiming at reducing mercury emissions and preventing human exposures [40]. The UNEP/WHO project funded by the Global Environment Facility (GEF) will aim at developing a global scheme for monitoring environmental 
concentrations of, and human exposure to, mercury under the Minamata convention. The project will be implemented in 2014-2016. Due to the ongoing efforts to develop a harmonized approach to HBM surveys in the European Region, the WHO ECEH office in Bonn will be responsible for developing standardized methodology for HBM surveys. The office will also organize pilot surveys in five countries which will be selected using a set of criteria in order to cover various exposure sources as well as geographic and socioeconomic conditions. It is envisioned that the surveys will focus on assessing prenatal exposure to mercury and will involve women in maternity clinics.

\subsubsection{Conclusions}

The conditions and HBM data availability vary greatly from east to west in Europe. WHO Europe facilitates the application of harmonized data collection methods in order to close the existing data gaps and produce internationally comparable data for monitoring the implementation of Parma Declaration Commitment to Act and the Minamata convention.

\section{Questions}

1. How are the priority areas chosen? Is only Eastern Europe included?

Priority areas for WHO surveys have been chosen to address important public health concerns and provide support to countries which lack internal resources or expertise to conduct HBM programs on their own. Countries for the UNEP-WHO project on mercury monitoring will be selected using a set of jointly developed criteria in order to address a variety of exposure scenarios in different geographic regions. Western countries are welcome to participate in the WHO projects.

\section{How was the priority set of chemical contaminants selected?}

There have been WHO technical meetings involving specialists from the Member States to assess this. The cost of analysis was an important consideration. The current version of the methodology focuses on metals because they are cheaper to measure. Biomarkers of selected organic pollutants can be added later. 


\section{Is there a program for measurements of chemicals in mother's milk?}

Many countries have national monitoring programs for POPs in human milk. WHO and UNEP coordinate an international survey of mothers' milk for persistent organic compounds.

\subsection{Biomonitoring results as support for precautionary policy decisions (Science - Policy - Decisions)}

Prof. Philippe Grandjean, Dept of Environmental Health / Harvard School of Public Health; Head of Dept. of Environmental Medicine / University of Southern Denmark. Author of the book "Only one chance".

\subsubsection{The biology of the brain}

The brain requires 20 watt to run while a computer would need all the power needed by the city of Stockholm to manage the same processes as one brain does. Even if it does not require much energy to run, it is a vulnerable organ. In the third semester of pregnancy, about 12,000 nerve cells are formed every minute in the fetal brain and these cells can migrate 1,000 times their own size. Up to 1,000 new synapses are formed per second postnatally. The collected axons of a 20 year old human can be wound 4 times around the earth. All these features and processes must take place at the right time and in the correct sequence and are therefore highly sensitive to disruption by environmental factors such as exposure to chemicals and malnutrition.

According to current practises, the decision on chemicals management need to be evidence based, and for this reason, it is lagging behind and thus exposes humanity to risks. The risk assessments also do not take the vulnerability of the brain and, particularly, brain development into account. Risk assessment and risk management should focus on the most sensitive periods in human development, i.e. most importantly during the prenatal and neonatal periods but also continuing through puberty when brain development is finally complete. It is during these sensitive periods that environmental hazards can do the most harm. Professor Grandjean terms the detrimental effects of industrial chemicals on brain development as a "Chemical brain drain" [41]. One very important responsibility we have is to protect the developing brains and those of the coming generations from chemical drain. HBM can and 
should be used as a trigger for policymaking and legislation within the field of chemical hazards to human health.

\subsubsection{Undesired agents passes the placenta}

In 1941 it was realized that measles (at that time not yet identified as a virus) could pass through the placenta which clearly was not such an effective barrier as it was thought to be. Mothers' exposure therefore equals the foetal exposure in many cases. The origin of health and disease starts in early life where exposures are imprinted during developmental programming. These exposures might affect the functional maturation which can lead to neurological disease and/or degenerative changes. Genetic predisposition also needs to be taken into account. One example of this is a common mutation which makes some individuals 10 times more susceptible to neurological damage from prenatal methyl mercury exposure. The impact on the next generation is particularly apparent from children getting smarter as lead exposures decrease in the population. This can be seen as an increase in 9th grade math test results in the population when lead levels fall (the study was performed in Massachusetts and covered children born between 1992 and 1999). The placenta does not protect against lead and other chemical brain drainers, hence it is important that pregnant women are protected against such exposures.

\subsubsection{The error in the traditional way of thinking}

Industrial priorities have affected the way of thinking for decades, thereby delayed interventions to protect us from exposures to hazardous chemicals. This approach is irresponsible for public health, where prevention against hazards would seem appropriate even in the absence of solid proof. On the contrary, claims have been made that new knowledge on environmental toxicants represented false-positive reports that could be ignored. Lately, "The Economist" magazine has criticized science as an insufficient basis for decision-making and has asked its readers to vote whether science should be believed. In contrast, the publication "Late lessons from early warnings" published by the European Environment Agency sheds light onto this problem from the point of view of the precautionary principle $[42,43]$. Because there are lots of un-investigated compounds and because untested substances are assumed to be innocuous, most probably these chemicals include lots of "false negatives" simply due to the lack of testing. The fear of false positives is misleading as these are 
very uncommon. The problem is instead all the compounds which have not been investigated. A new way of decision making and regulation needs to be developed to tackle this problem.

The different level of knowledge concerning neurotoxic chemicals can be illustrated as follows:

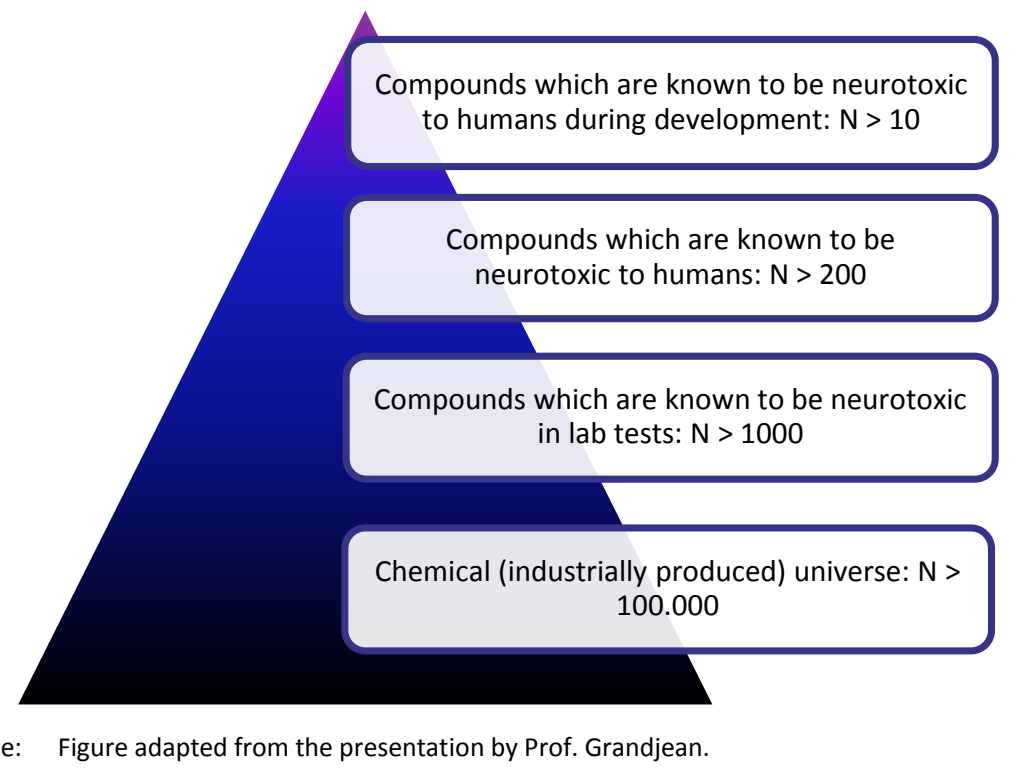

More than 200 neurotoxic compounds are known to enter the human brain and cause neurological symptoms, and out of these, only a dozen have been identified as causative agents for developmental defects_such as reduction in intelligence and behavioural changes [44]. The identified compounds include arsenic, lead, mercury, manganese, fluoride as well as PCB, brominated flame retardants and some organic solvents and pesticides. But, with time, even more are going to be identified. We have a silent pandemic of ADHD and other less easily recognized neurological syndromes [45]. These are new findings that the decision makers and the population at large need to acknowledge and they need to be taken into account when planning HBM.

\subsubsection{A new way of science and policy making is needed}

There is need for a new science - policy making interaction involving HBM. Consumers can make choices if they have the correct information. This would need correct labelling on all products as well as knowledge of occurrence of contaminants in food, water and nature. But, according to the Aarhus convention, people have a right to know what they are ex- 
posed to. As a new approach, HBM could be used initially as a stimulus for policy development, rather than the more traditional way which starts with discussions concerning if there is a hazard, if exposure limits are needed and how to utilize HBM. In this case, HBM would instead provide a direct answer and could stimulate actions at a much earlier time. Such bottom-up approach would also provide stimulation for environmental health research, where currently only a few compounds dominate the scientific literature, such as metals, PAHs, PCBs, ethanol and benzene. Studies with a wider scope are warranted and could appropriately begin with chemicals demonstrated by HBM to be present in exposed populations.

While prevention and technological development are often said to be costly in terms of medical costs, the effect of chemicals on brain development has a high cost and accounts for suffering as well as severe economic loss for the affected individuals. Taken all together, this exhibits an enormous economic loss for society.

There is need for a clearer connection between science, environmental medicine and policy making. However, this is counteracted by the factors mentioned under the paragraph concerning the traditional way of thinking as well as the following limitations of science as basis for decision making:

- Not enough systematic testing.

- Inherent inertia in science.

- Skepticism towards new science.

- Uncertainties result in hedged conclusions. 


\section{A new science-policy interface}

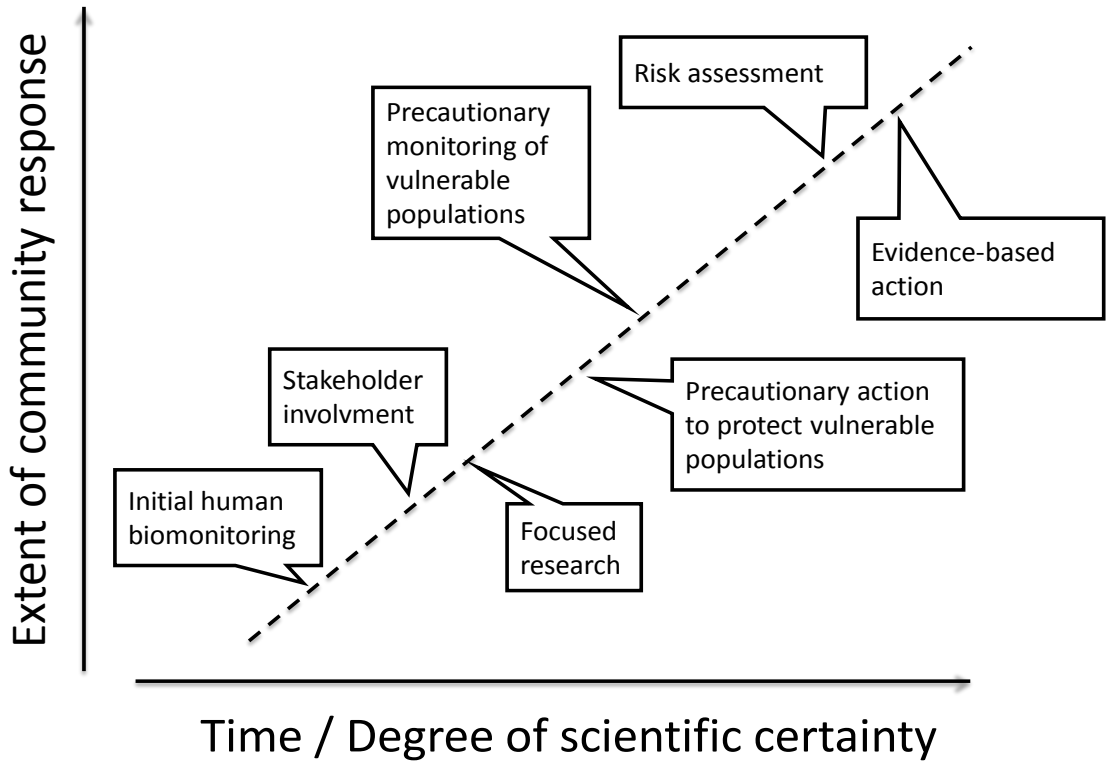

Kilde: Figure adapted from the presentation by Prof. Grandjean.

\subsubsection{Conclusions}

Consumers in general and public institutions can make choices to decrease exposures of industrial chemicals, but the ultimate responsibility lies at a higher level in society. Proper protection should involve the right-to-know, as expressed in the Aarhus Convention, where HBM could provide individuals with knowledge on their exposures, the risks coming from these exposures and the need for prevention.

Evaluation of industrial chemicals and biomonitoring of these need to include focus on early development and factors which affect the developing nervous system. Protocols to test chemicals for developmental toxicity are already available from the Organisation for Economic Cooperation and Development (OECD). These types of tests have to become standard procedure, not only for new compounds; the ones which are already on the market should also be included. An international clearinghouse is needed to coordinate these efforts [45].

Professor Grandjean finishes with a statement and task to the audience:

"Scientists need to stand up for human health!" 


\section{Questions}

1. We are good at measuring chemicals, even at low concentrations, but how about the "unknown" chemicals (new industrial chemicals etc). How to deal with this?

This needs to be discussed - there is no easy solution. We need new models to do better. HBM can be one indicator and we need transparent and democratic procedures for decision making. HBM is an important tool; ethicists say that we have a right to know what contaminants that are present in our bodies. Consumers should also be regarded as stakeholders, alongside the private sector and regulatory agencies.

2. The human brain is more complicated than that of any other animal. Does this mean that we cannot test neurotoxic compounds on other species?

OECD protocols use rodents which is an expensive procedure that provides information very slowly. We need to use human brain stem cells. A panel of cell culture tests can give the same or better results than animal tests. It will also be cheaper, faster and not involve the sacrifice of animals.

3. Can we do better with in vitro assays (cell assays) than animal tests?

Yes, but we are not there quite yet. These methods are not completely ready for use on large scale. These tests need to be included as standard in REACH, for example, to test for EDC and neurotoxicity.

\subsection{The Aarhus Birth Cohort Biobank}

Ass. Prof. Bodil Hammer Bech, Dept. of Public Health, Institute of Epidemiology and Social Medicine, Aarhus University, Denmark.

\subsubsection{The aims of The Aarhus Birth Cohort Biobank}

The Aarhus Birth Cohort Biobank was established in 2008 with the aim of conducting HBM measurements focusing on monitoring of reproductive as well as fetal endocrinology and early programming [46]. Furthermore, biological understanding of associations between environmental exposures and health outcomes were to be assessed. Lifestyle and gene-environment interactions were also to be taken into considera- 
tion when assessing disease incidence in newborns as well as later on in their life. For example, the association between low birth weight and higher risk for coronary heart disease_was found [47]. Blood from mother, father and the umbilical cord of the newborn are collected; there is also a tissue sample collected from the umbilical cord.

The project is funded through The Danish Council for Independent Research, Danish Council for Strategic Research, A.P. Møller Foundation for the Advancement of Medical Science, TrygFonden and Aarhus University Research Fund.

\subsubsection{Earlier activities and standards of sampling and handling of samples}

Within the ongoing Aarhus birth cohort which has been active since 1989 (the above mentioned biobank is an amendment to this project), questionnaire data from pregnancy and data on birth outcome have been collected from about 100,000 pregnancies. The data can be linked to hospital data during the lifespan of the sampled newborns.

There was a national birth cohort with collection of blood in 19962002 in Denmark, but too low volumes of blood were collected and the standards of sampling and shipping were not adequate. In the Aarhus Birth Cohort biobank, larger sample volumes are collected and better sample quality is assured. The sampling is standardized by storage at $+4^{\circ} \mathrm{C}$ before freezing with less than 2 hours until freezing at $-80^{\circ} \mathrm{C}$ and storage and freeze-thaw cycles noted. The umbilical tissue is frozen within 24 hours depending on the time of birth. There is a link between the parents and baby with specific numbers for each individual, 40 new families are recruited per week $(11,500$ families have been included since the start in 2008 of which $62 \%$ are complete with samples from the mother, father and baby). From August 2008 until December 2011, a PAXgene blood RNA tube was additionally collected from the mothers (6,877 participants). The register in the database includes: personal identification number, biobank number, ID Number (Aarhus Birth Cohort), type of sample, type of preparation and storage history. New ideas can be incorporated at any time such as more sampling, new questions in the questionnaire etc. Due to the standardized treatment of the samples and the large volume it will be possible to perform studies on biomarkers with short half-life (cytokines), environmental exposures (e.g. diet-related), toxicological status (e.g. xenobiotic chemicals), genetic status (including family trio design) and gene-environmental aspects. 


\subsubsection{Ethical approval and research}

Ethical approval is needed when the samples are going to be used. There is consent by the participants to the storage of samples and data usage which might be withdrawn at any time and the samples will then be discarded from the biobank. It is expensive to run the biobank and researchers have to provide funding to use it.

There is currently one research project, FETOTOX, which uses the biobank [48]. This project aims to study the interaction between motherfetus exposure to environmental toxicants and risk for adverse effects on development. It also investigates whether persistent organic pollutants in the blood of pregnant women affect fecundity, the growth of the fetus and later development.

\subsubsection{Conclusions}

The Aarhus Birth Cohort Biobank is and will be a valuable resource in future studies (especially in the area of fetal programming) where biological materials are necessary.

\section{Questions}

1. Where do you get funding?

From the Danish Council of Science as well as from private funds; the project is funded through 2015 as it looks now.

2. Do you take dietary information?

No, very little, intake of supplements is the only parameter which is registered.

3. Do you take urine samples?

No, only blood samples.

4. How are the scientists who are allowed to use the biobank selected?

They have to make an application; only one group has done that so far. 
5. Why do you only store $4 \mathrm{ml}$ blood from the father?

Because we only worked with the mothers at the start - the blood from the father is mostly stored to have the DNA.

6. What is the participation rate?

$45 \%$ of the asked couples want to participate. (It is done at Aarhus University Hospital which might increase the participation rate).

\subsection{Persistent Toxic Substances, environment, climate change and human health effects in the Arctic}

Prof. Jon Øyvind Odland, Dept. for Public Health, the Arctic University of Norway.

\subsubsection{The Arctic council and the Arctic monitoring and as- sessment program}

The Arctic council is a unit composed of representatives from organizations of indigenous populations with respective Arctic countries as observers. Other organizations are also involved as observers. The Arctic council has subgroups focused on different issues concerning the arctic region. Within these groups there is focus on contaminants and health. The subproject where these issues are included is called Arctic Monitoring and Assessment Program (AMAP) [49]. The geographical area includes northern Russia, northern Scandinavia, Greenland and Svalbard, Canada and Alaska. In general, the life expectancy is lower and the infant mortality higher in the arctic region which has four million inhabitants. Most of these reside in Russia which makes collaboration with the WHO project presented earlier the same day by Dr. Egorov an intriguing opportunity. The climate change is already happening in northern Russia the permafrost is melting. The Arctic region is a victim of global pollution. Mercury levels, as an example, were decreasing but are now stabilizing and even increasing.

\subsubsection{Previous studies, exposure measurements and the effects of global warming}

In the Tromsø study which was performed between 1979-2007, samples were collected from the same persons during the whole time span which gives a great potential in assessing health outcomes connected to 
chemicals present in the blood about 30 years earlier. There is also a new report on mother's milk consumption from Norway by Bertelsen et al. [50]. When assessing fetal exposures, it is important to know that the cord blood is a mixture between the mother's and the baby's blood. Specific care has to be taken if the aim is to achieve a sample of the baby's blood only. It is therefore of importance to have standardized protocols for sampling.

Concerning PCBs, if the levels in women would be as high as some levels measured in men during the 60's, we would have an even larger problem. Half-life for PCBs ranges between 30-50 years; while DDT levels go down, PCBs are more stable. DDT is accepted for malaria prevention in warmer countries. However, it is not clear what will happen upon climate change when malaria will spread. Flame retardants such as PBDE affect sensitive marine animals such as polar bears and beluga seals and the highest PFOS levels were found in polar bears. These increasing levels of contaminants in animals follow the increase in production. The effects are first manifested in these animals, subsequently effects will undoubtedly be observed in humans. We have good programs for known contaminants, but focus is also needed on emerging pollutants. Many of the newer pesticides are now seen to increase in the Arctic region. There is a gradual change in exposure of the population through health advice, food sources and the consumer's active choices.

The contaminants found in the arctic region nowadays were earlier not even imagined to be present there. Since those compounds may travel long distances from production and use, high levels are present in the Arctic. These compounds have been accumulating in the ice and are now being released in a process which requires thorough monitoring since tons of ice are lost from Greenland. The climate change affects the availability of POPs also in other ways than the release from the melting ice. These ways include changes in the rate of mobilization from materials, shifts in the partitioning between air and soil/water as well as increased release from other environmental reservoirs. This might increase the exposure to POPs and is discussed in detail in the 2011 UNEP/AMAP report "Climate change and POPs: Predicting the Impacts" [51].

\subsubsection{Protecting the indigenous population}

Indigenous populations need protection both of themselves and their traditions. An example is the consumption of liver from seal which is traditionally fed to children by Inuits. The seal liver is a largely contaminated product containing high levels of PCB and other environmental contami- 
nants, but feeding children with this has been a tradition since the seal liver is very nutritious. To ensure the protection of these populations and their traditions, sustainable development is needed throughout the globe in order to decrease the contaminant load on the environment. Health assessment of the Arctic populations has been performed regularly over the last years to monitor the effects and exposures, i.e. 1998, 2002, 2009 and is planned to 2015. POPs are also monitored in air.

Epidemiology cannot give clear cause-effect connections, only associations.We have a global environment and no one is protected due to the movement of pollution in air and water. There is a lack of understanding concerning the effects of climate change on the food web structure and dynamics. An EU project called "Arctic Health Risks: Impacts on health in the Arctic and Europe owing to climate-induced changes in contaminant cycling" (ArcRisk) is concerned with these effects [52]. Mixtures and metabolites of contaminants also need to be taken into account. Many different disciplines are involved in the assessment of combined effects, from cellular models to human and environmental monitoring. Application of the precautionary principle is beneficial but it has to be utilized more extensively. Lower levels of certain POPs such as dioxins, PCB and DDT are present after the introduction of regulations. Contaminants are unavoidable but need to be at a sustainable level.

\subsubsection{Conclusions}

Why is it difficult to conduct HBM?

- Cohort studies are done over an extensive amount of time.

- Few participants.

- High cost.

- It is difficult to measure the outcomes from the observed contamination.

- Confounder problems.

- Are we even measuring the right chemicals/ biomarkers?

- The observed effects are often within the normal variation.

- Problems assessing mixtures and combined effects; taking metabolites into account. 


\subsection{Use of human biomonitoring in risk assessment for food safety}

Ass. Prof. Anders Glynn, Risk Benefit Assessment Unit, National Food Agency, Sweden.

\subsubsection{Nutrition and exposure at an early age - The moth- er's milk survey}

The first mother's milk survey in Sweden was conducted by the Swedish Public Health Institute in 1970. These samples came from the Stockholm area and sampling has taken place regularly since then. In this survey, pooled milk samples have been analysed. In 1996 a more comprehensive survey started in the Uppsala area, close to Stockholm, in which individual milk samples are analysed. The results from the surveys show that infants are exposed to a wide variety of environmental pollutants from consumption of mother's milk. To take some examples, PBDE levels were at 500-4,000 pg/g lipids between 1972-1996, and are at present decreasing in general [53]. However, the last PBDE to be regulated, decaBDE, is still seen at stable levels in the population. PCB and PCDD levels in mother's milk have decreased considerably since the early 1970s, and the trend has continued over the last 15 years. Hopefully, in approximately 30 years body burdens in pregnant women might be acceptable from a health point-of-view (the current levels are at or slightly above the reference limit set by US EPA). Perfluorinated compounds, PFC, or more specifically perfluoroalkyl substances/acids (PFAS/PFAA) are a new group of contaminants of which many compounds are increasing in concentration in humans. These compounds are mentioned further in a paragraph below.

\subsubsection{Exposure to mercury and flame retardants from food sources}

Methylmercury levels are high in freshwater fish in Sweden and there is a correlation between high consumption of freshwater fish and higher levels of methylmercury in sub-populations with that type of diet [54]. Despite this fact, the mean total mercury levels in hair are similar throughout the country and the levels in the cohort of first-time mothers in Uppsala continue to be stable.

The human intake of flame retardants BDE-47 and BDE-99 from food has gone down in Sweden since the mid 1990's when the maximum was 
reached [55]. There is also a downward trend in mother's milk from the Uppsala and Stockholm area. Opposite to this, BDE-209 (deca-BDE) is not decreasing but continues to be at a constant level at $1 \mathrm{ng} / \mathrm{g}$ lipids. Proper management and limitation of the levels of contaminants in animal feed result in lower intake levels from food consumption in humans.

\subsubsection{New contaminants from unexpected sources}

When measuring PFAS, the results from the study of blood serum levels in Uppsala show that PFOA and PFOS decreases while perfluorohexane sulfonate (PFHxS) and perfluorobutane sulfonate (PFBS) increases [56]. PFAS are difficult to measure in milk since the levels are generally very low. It is easier to measure in serum due to much higher levels. The increase of PFHxS and PFBS in the Uppsala population is not from contaminated food but rather from drinking water. The source of contamination is suspected to be a military airport, where foam for firefighting exercises containing PFAS has been used. At Swedish airports, levels as high as $100,000 \mathrm{ng} / \mathrm{l}$ in groundwater have been measured. A highly contaminated site is Kallinge, close to Ronneby, where the PFAS levels levels in drinking water have reached $10,000 \mathrm{ng} / \mathrm{l}$. In this area, a military airport is situated on top of the groundwater aquifer which is the source of drinking water in the area. A biomonitoring study shows that the contamination is reflected in very high exposure among 12-year old children. It is predicted that many more drinking water sources in Sweden will have similar problems within the next 10 years. A manual for risk assessment of PFC in drinking water has been published by the Swedish Chemicals Agency and the National Food Agency in collaboration. All counties in Sweden have been notified to make assessments of their drinking water sources in order to protect the population from high exposures $[57,58]$. This is not only a Swedish problem; it most probably exists in other countries which have/had similar activities.

\subsubsection{Conclusions}

HBM is an important tool in identification of emerging pollutants and sources of exposure as well as for follow-up of risk management decisions. HBM data are also useful for risk and benefit assessment of food components. The identification of drinking water as an important source of PFAS exposure was made possible by the availability of HMB data spanning over many decades. This illustrates the importance of continued general HBM programs. 


\section{Questions}

1. The limit which was set for these compounds is $90 \mathrm{ng} P F A S / l$ water, is this lower than the EFSA TDI?

The TDI for PFAS was used and it was assumed that a maximum of $10 \%$ of TDI was coming from drinking water. The drinking water limit was set for the sum of 7 PFAS that are most commonly found in drinking water in Sweden. Some of those PFAS are not as bioaccumulative as PFOS, but new data suggests that some PFAS are more toxic than EFSA's assessment states.

2. How's the comparability ensured between the different years' measurements?

The sampling is standardized. Most often the same lab is used for analysis and also, there are standards to use.

3. Does Sweden have that much military?

The air force was a large part of the military and there was compulsory service for all men until recently. But PFAS contamination is not a Swedish problem alone. It is probably common throughout Europe. 


\section{Debate: From human bio- monitoring to regulations - lessons learned}

One of the aims of this seminar was to achieve exchange of knowledge among the attendants. That part was considered done since information was shared and the participants learned from each other.

During this session a number of questions arose, some of which were: How do we apply HBM data in policymaking today? How can improvements be made? Who is in charge of the precautionary principle? On the environmental scale, which areas should be selected based on HBM as a tool?

The text below is not a consensus statement but represents opinions and suggestions from the participants.

The function of HBM as a tool in policy making was discussed. The policy makers should be well informed when taking decisions on reforms, bans, legislation and recommendations concerning public health. HBM data can aid in this process. Generally, some provocation is required for humans to take action, whether it is consumers who start to make informed choices or politicians who make new policies. There is a need to take several subsets of biomarkers into account to get the complete picture of human exposure to hazardous substances. Different legal bases exist depending on the area of concern, such as food, drugs, cosmetics etc.

One problem of HBM is that there is a lack of suitable methods for certain contaminants, especially emerging ones. Moreover, HBM programs are relatively expensive. The methods are in constant need of development and to achieve this, collaboration is necessary. We do not know today how we can/will use the samples or answers from questionnaires tomorrow, they might be useful later, hence the importance of biobanking.

One opinion was that when bans exist for certain compounds, for example plasticizers in food contact material, monitoring is not needed for this source. But, such compounds might still be present in the population at alerting levels and other sources need to be investigated, for example drinking water. HBM can be part of the solution, but should be based on 
environmental monitoring in order to identify the source of exposure. As with the firefighting foam, it would have been better to measure the drinking water first and applying HBM afterwards. It is hard to find the source if starting with HBM data. If not knowing the source, it will also be hard to explain the problem to the participants, i.e. why they are exposed.

An opposing opinion to this was that it is not necessary to identify the source first, because in that case, we do not know what to analyze. For example, there are many sources of exposure to plasticizers and HBM can be used to get valuable information on the total exposure over time. Plastic ingredients are an important group of contaminants and consumers can modify their behavior to avoid certain chemical exposure. HBM is very useful in this case and can supply information on how modified behavior by the consumer affects the exposure. Appropriate use of HBM together with information on the sources of contaminants is useful. This can give valuable information regarding contribution of different sources to the total exposure. Thus, HBM strengthens the capacity to make informed risk management decisions as well as follow up riskreducing or preventive actions.

HBM can be used as an early warning system and is therefore very important. It can provide the first examples needed to give action and be used to assess the exposure to new contaminants in the population. Even if we do not have proof for toxic effects, it is still of interest to monitor exposures, in order to be able to take action before problems arise. This can also influence political decisions and regulations. We also need to know how the specific chemicals behave in the body. When comparing the costs of HBM programs in the general population to the costs of different population subsets studies, they are higher for investigation of the latter. It is still of importance to assess the effects of exposure to contaminants in those groups specifically and the costs need to be taken to prioritize these investigations.

One opinion was that for HBM to be effective when trying to identify and combat emerging problems, the right of the consumers to know "what is out there" should be prioritized. REACH is not enough to limit the compounds which need restrictions. The industry needs stricter regulation. Otherwise, the problems connected with exposures to harmful compounds which humans are facing today will persist.

What information do we get out of these studies and out of food questionnaires? What is the importance of dietary data? How to address the difference between the level of detail gained versus high participation rate?

It is possible to get solid information in studies with relatively few subjects. However, if the study involves a large amount of participants, it 
might happen that lesser detail is gained. Food should be analyzed as a complement to HBM. To analyze specific food items is costly; therefore analysis of food groups is a less expensive alternative. Intake calculations have to be done carefully; otherwise the error can easily be an order of magnitude. A valid question is which age groups that are considered? Naturally, children cannot respond to the same questions as adults. The design of questionnaires and the choice of questions are important factors, which have to be carefully evaluated for each group of participants.

Are there ethical problems? An application has to be made to the ethical committee for approval before the study can be conducted in order to assure that there are no concerns of this kind. When children are included, more ethical considerations arise. If there would be some alerting findings from the sampling of children, action has to be taken directly. In general, HBM is very useful and has more positive aspects than negative ones. But there is need for solid grounds when the decision is taken to use HBM. There are many different chemicals and exposures to measure and it takes careful evaluation to know which HBM application that is most suitable for every specific case. When it comes to evaluation of consumer health and exposure, use of HBM is an obvious choice.

The Swedish EPA have discussed early warnings and concluded that it is almost impossible to identify those signals. While it is possible to follow effects of actions taken earlier, it is impossible to do preventive work, simply because it is not known which chemicals to look for. One advantageous strategy is to plan HBM based on results from environmental monitoring.

Since the topic of PFAS exposure from firefighting foam was addressed during the last presentation, the participants enquired how the exposure to PFAS is among firefighters. No studies are done on this subpopulation in Sweden so far but The Swedish Civil Contingencies Agency has one in progress. The firefighters are probably exposed to high concentrations of PFAS and the expectations are to find higher levels among them compared to the general population.

How useful is HBM of contaminants from food sources versus epidemiological studies? In Kallinge where the extremely high levels of PFAS were found there is a clear benefit to assess the association between the contamination of the food (drinking water), levels present in individuals and health outcomes in the affected population. Measurement of contaminants and epidemiological studies complement each other and are both needed. 
An information poster about the strategies of Health Canada was given by seminar participant Julie Yome [59]. The poster summarized the efforts made by the government of Canada to advance and improve the management of chemical substances and safeguard the health of Canadians. In the field of biomarkers, the Chemicals management plan includes targeted environmental and population biomonitoring, biomonitoring supportive research and national biomonitoring. The latter including the Canadian health measures survey, Northern contaminants program, Maternal-Infant Research on Environmental chemicals and the First nations Biomonitoring initiative [60-63]. 


\section{Discussions}

On the second day of the seminar, the participants were divided into four discussion groups. A chair and a secretary were appointed to each group. A number of questions had been compiled beforehand by the organizers, which were used in the group discussions. Before the discussions started, a summary from the first day was given by the organizers and the groups delivered take home messages from day one.

\subsection{Reflections from Day 1}

- How do we apply HBM-data in policy making today?

- It is applied when achieving, for example, the relative contribution and routes of exposure, or identifying temporal trends. HBM data has been used when taking decisions, for example when determining to phase out lead in petrol and when taking action against human BPA exposure.

- Should we use HBM data as an early sign of future problems? (Emerging risks).

- There was a mixed response in the audience, it depends on context and is beneficial sometimes but not always. Ethical considerations were up for discussion in connection to the suggestion. The opinion was raised that it is still important not to measure only the known problems including health effects but also suspected and emerging ones (could be only exposure). Both HBM data on exposure and effects are important, however, biomarkers of effect are not used very often. HBM can be used to validate "traditional exposure assessment" and/or to complement existing knowledge. The results from environmental screening programs could be used as a platform when identifying certain substances to include in HBM studies. Also, non-target screening of human samples is an upcoming tool which will hopefully predict emerging risks in the near future.

- What are the limitations in the current HBM programs as a tool towards consumer safety? 
- Early warning seems to be problematic. It can be feasible if supportive data is available enabling source attribution. It is important that HBM is cost-effective (especially in the eyes of those who fund the programs). Improved collaboration is needed. HBM programs are expensive and might not, independently, provide enough information for management of risks. Quality assurance is important, including certified reference materials; proficiency tests of involved labs are vital in addition to monitoring of the entire process. Using combined assessment of different routes of exposure and different types of biomarker, like in exposome methods, is very costly. However, it yields valuable information. This justifies that continuously improved HBM programs including biobanks need support over time which is also true for all harmonization efforts, so called "The golden rule".

- What are the advantages in the current HBM programs as a tool towards consumer safety?

- HBM gives reliable data because it integrates all routes of exposure (and combined exposures) and circumvents discussions on pharmacokinetics in addition to trace sources of exposure (which demands questionnaires of different types). Dropout rates are low when people are recruited in hospitals or when they are provided with e.g. a free medical examination.

- How important are dietary data? How detailed should they be? Balance between level of detail and high participation rate?

- Dietary data are important in risk-benefit assessment. For example, nutrition and/or health status of an individual might affect metabolic capacity and the rate of elimination of toxic compounds from the body. Thus, dietary data can be used to confirm or refuse a hypothesis regarding exposure level and/or nutritional status. Food frequency questionnaire (FFQ) should be used for items not consumed regularly and more detailed registration for regularly consumed food. Duplicate diet studies are very valuable for validation of biomonitoring data.

\subsubsection{Take home messages from the discussion groups}

- NHANES is one of the world's largest HBM programs. It is therefore very important to follow the results of the studies and assess benefits and limitations in such a large program. 
- Contamination of ground water by PFAS was discovered by HBM, not in the environment. This illustrates the importance of continuous HBM programs.

- HBM can be used as a tool to monitor combined exposure, but integrating all sources of exposure is a challenge. There are spatial and temporal challenges in HBM as well as deviations between laboratories performing the same analysis.

- The future use of HBM needs to be addressed more extensively. Establishing connections between environmental monitoring and HBM is cost effective in most cases. HBM provides a very clear picture, for demonstrating and providing proof of exposure which is useful for actions and policy making. Environmental contaminants.

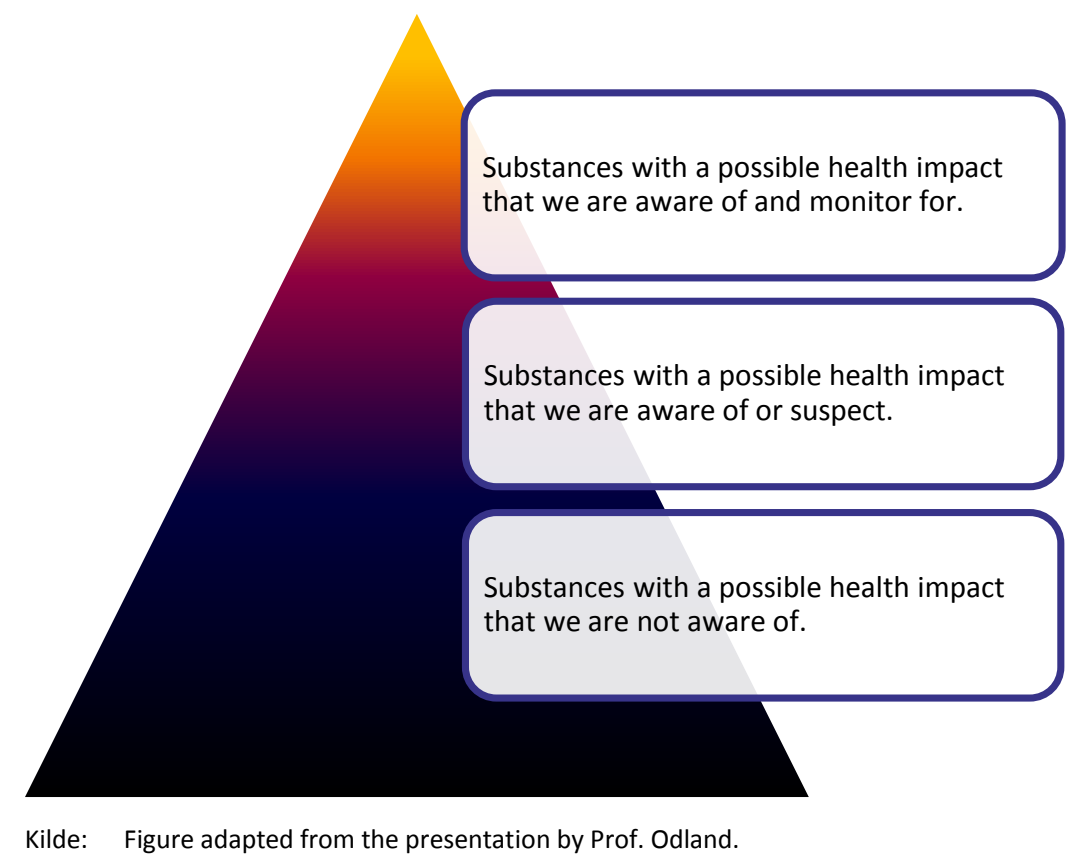

- A wide variety of small and large HBM studies are ongoing but most of them are not harmonized. In general, comparability is needed, but sometimes specifics are more important. There are different purposes in different settings. There is no question about the fact that more harmonization is needed but this applies mostly when a common purpose exists. 
- Biobanks are very important for use in HBM. One of the reasons is that it assures continuity in analysis of time trends in nutrition and exposure to contaminants. Furthermore, concerning biomarkers of susceptibility we cannot measure low level effects yet. Therefore, biobanks are needed to store samples until developed methods are available. The importance of networking and the power of human biobanks need to be addressed more extensively. Harmonization is important, especially within the use of biobanks. There are some ongoing activities, but more is needed of networking and integration. This calls for the current state of the art of HBM to progress; this is especially evident for HBM of exposure.

- Different purposes for HBM of exposure exist, such as assessing environmental exposure, exposure from food, occupational exposure etc. Consumer safety is most often not addressed properly.

- Different genotypes might give different susceptibility to certain chemicals and toxins. Moreover, the nutritional status and its influence on human health and/or exposure need to be assessed. Thus, it is not only the exposure to contaminants but also the genetic predisposition, nutritional status and body composition which determine the effects. Hence, the differences between genotypes need proper assessment and use of HBM is vital here.

- There is a wide use of HBM, but the choice of biomarker depends on the use and purpose. There is also need for priorities concerning the monitored substances. It was suggested that focus should lie on a few compounds, both for HBM as well as for environmental monitoring.

- Should the food questionnaires include many other parameters as well? Later on, more information might be needed if new questions need to be answered. It will therefore be beneficial to have extensive information on for example supplement intake and other individual choices as well as lifestyle factors. 


\subsection{Group discussions}

\subsubsection{Group 1 "Safe food and toxicology"}

Participants: Anders Glynn, National Food Agency, Sweden (chair); Ingrid Stavenes Andersen, Norwegian Food Safety Authority (notes/report); Lilianne Abramsson Zetterberg, National Food Agency, Sweden; Pertti Koivisto, Finnish Food Safety Authority, Evira; Gro Mathisen, The Norwegian Scientific Committee for Food Safety; Lisbeth E. Knudsen, University of Copenhagen; Pernille Mathiesen, Norwegian Institute of Public Health; Helle Margrete Meltzer, Norwegian Institute of Public Health; Thorhallur Ingi Halldorsson, University of Iceland; Marika Berglund, IMM, Karolinska Institutet, Sweden.

1. Propose and motivate five biomarkers which you believe are the most important in harmonized HBM of food-related exposure in Nordic countries. Discuss the possibility to use "new" biomarkers and/or techniques (emerging risks, exposome, metabolomics etc) in HBM. Are there needs and ways to collaborate between the Nordic countries?

$\begin{array}{ll}\text { Biomarker } & \text { Justification } \\ \text { Mycotoxins (DON) } & \begin{array}{l}\text { Related to the food-chain } \\ \text { Known health effects } \\ \text { Transfers to foetus } \\ \text { Seasonal variations }\end{array} \\ & \begin{array}{l}\text { Nutritional biomarker; important for foetal brain development } \\ \text { Reduced intake due to reduced consumption of milk products among the } \\ \text { lodine }\end{array} \\ \begin{array}{l}\text { young population and decreased consumption of iodized salt } \\ \text { This might be a hidden problem since the change in iodine intake from the } \\ \text { diet has occurred slowly }\end{array} \\ \text { Esed broadly } \\ \text { New emerging compounds, substitutes for the "old ones" } \\ \text { Focus on new fluorinated compounds or break-down products } \\ \text { Phenolic compounds }\end{array}$

2. What is the role of "biomarkers of exposure" and "biomarkers of effect" in risk assessment and which of them is most useful?

Biomarkers of exposure are closely connected to the source, while biomarkers of effect are closer to the health effect/disease. The choice of biomarker (effect/exposure) should be determined on a case-by-case 
basis. If the aim is to determine levels of contaminants or nutrients in humans, biomarkers of exposure should be used, while if a connection between the exposure and health risk is desired, biomarkers of effect should be included.

For policy making, we need to monitor the biomarkers of exposure since it is not possible to establish new policy which is solely based on an observed biological effect. On the other hand, if testing hypotheses when established links to health effects or knowledge of the exposure already exist, the biomarkers of effect will be most useful. The ideal system is flexible and allows for the investigation of both types of biomarkers, for example as in NHANES.

\section{How to overcome problems to involve representative cohorts (number of participants, age, social status, immigrants etc.)?}

Several different approaches to involve different cohorts were discussed, such as blood donors, women having mammograms, examination of men liable for military service and pregnant women (with father and newborn) in hospitals. The experience from the group is that the more targeted the study is, the better representation. Furthermore, if the participants have a special worry or concern (e.g. pregnancy might motivate the subjects to show increased care for their health), a high level of participation and better representation than in other groups might be achieved. However, depending on what we investigate, not all cohorts need to be representative in every aspect. In the case of plasticizers for example, it is believed to be little variation in exposure within and between social-economic and ethnic groups.

There is a challenge in involving immigrants. Several members of the group have been primed to this challenge. In general, the participation of immigrants (probably certain groups of immigrants) is low if the inquiry to participate is sent by post/mail/telephone. Therefore, a general study will lack this information. Also, it has been observed that certain groups of immigrants have quite different levels of pesticides, nutrients, heavy metals, etc. compared to the native population. Therefore, recruiting of immigrants is considered important. The best success involving immigrants have been achieved by targeted studies, where special focus on involving immigrants has been performed. One example mentioned, was the success achieved through a targeted "door-to-door approach" in Oslo, Norway. Studies especially targeting the immigrant population have also been conducted in Gothenburg. Smaller studies of immigrant populations can be performed in any Nordic country based on the general studies to investigate whether or not nutritional status and/or contaminant exposure in immigrant populations deviate from the general popu- 
lation. Furthermore, recruitment of pregnant women in hospitals/health stations can increase the immigrant participation rate.

Based on this, the group believes that recruitment of pregnant women (and their family) in hospitals will give the best representation, both concerning number of participants, age and social status. However, more targeted studies on certain ethical, religious or other groups, might be necessary. In addition, we need to know the socio-economic background to do adjustments afterwards, i.e. to be able to balance out biases in representation to a certain degree.

\section{How do we relate biomarkers of exposure and effect to human health risk? How to improve HBM-surveys in order to reach a sustainable framework for HBM? Motivate if there is a need for collaboration between Nordic countries.}

This was believed to be best achieved through the use of follow-up studies / prospective studies. An advantage would be if the results from the participants can be linked to the health registries. Since we only get a "snap shot", repeated sampling is recommended to be able to establish a causal link between exposure and effect. Toxicological- and pharmacological knowledge and experiments will still be needed to test, supplement and support HMB findings.

Nordic collaboration and harmonization gives clear advantages. It is especially strategic for funding opportunities and it gives bigger momentum to stand together. It would also give higher efficiency, larger participant number, lower cost (e.g. for laboratory services) and will also be more powerful for influencing policy decisions at national and/or EU level. Collaboration will also facilitate exchange of information between Nordic risk managers since they will have access to the same background data. This also gives the advantage of focus on the same issues simultaneously which will yield more power when influencing policy development and decision making. Collaboration should be harmonized, but leave room for specific issues of national concern. One issue concerning Nordic collaboration is that it takes time to organize and requires funding per se.

\subsubsection{Group 2 "Nutrition and Human Biomonitoring"}

Participants: Irene Mattisson, National Food Agency, Sweden (chair); Anna Karin Lindroos, Swedish National Food Agency (notes/report); Iris Erlund, National Institute for Health and Welfare, Finland; Agneta Åkesson, IMM, Karolinska Institutet, Sweden; Bryndís Eva Birgisdóttir, Landspitali University Hospital and University of Iceland; Inger Therese Lillegaard, The 
Norwegian Scientific Committee for Food Safety; Eha Nurk, National Institute for Health Development, Estonia; Mette Holm, Ministry for Food, Agriculture and Fisheries of Denmark; Merethe Steen, Norwegian Food Safety Authority.

\section{Propose and motivate five biomarkers which you believe are mandatory in HBM of nutrition/health status in the Nordic countries}

The following nutrients and health parameters were discussed in the group: iodine, sodium, potassium, magnesium, selenium, vitamin D, iron, vitamin C, folate, vitamins B12 and B6, antioxidant status in general, blood sugar levels (for example by HbA1c). The following nutrients/health parameters were singled out as the most important variables, although other variables may also be important depending on purpose and context:

- Vitamin D. For policy reasons it is important to monitor vitamin D since low vitamin D status may be associated with adverse health outcomes. Vitamin D intake is generally low in certain segments of the population. If the levels of fortification and number of fortified foods are to increase, monitoring of the population to evaluate the outcome of the fortification is important to ensure its safety and efficiency.

- Iodine. For maintained health of the population and policy reasons it is important to monitor iodine as deficiency may lead to negative health outcomes, especially for the fetus. If levels of fortification and number of fortified foods are increased it is important to monitor the population to evaluate that increased fortification has the intended effect and to ensure that individuals and groups do not get an excess of Iodine (monitor safety).

- Sodium and potassium. Policy strategies to reduce sodium intake need to be evaluated. This could be done by monitoring sodium intake. If urine samples are used to measure sodium levels, potassium levels can be measured in the same samples. This can be used as one estimate of healthy eating behavior.

- Iron (ferritin). Iron deficiency is a problem, particularly among young people.

- Folate. Deficiency of folate may lead to negative health outcomes and adverse effects on the fetus. Adequate folate levels are important both before and during pregnancy. Folate could also be used as a marker for fruit and vegetable intake. 
- In addition the group thought that selenium is an important compound to monitor (safety, deficiency).

\section{Is there a need for harmonization of dietary data in the Nordic} countries to improve risk-benfit assessment? If yes - which data should be harmonized and how would Nordic countries benefit from collaboration?

Nordic countries are relatively small and, for this reason, need to collaborate. These countries have very good population registries which makes it possible to combine data. Disease registries are already harmonized in the Nordic countries. By combining data we can get larger sample sizes. It is essential to harmonize laboratories for different types of analyses in order to be able to compare data.

A possible project to collaborate on is HBM of iodine. It might be possible to receive funding from NKMT for a project to measure iodine status in the Nordic countries. ${ }^{1}$

\section{FFQ and open food registrations/recalls: which one and why to choose in HBM?}

Concerning regular dietary surveys, the Nordic countries move towards 24-recall methods as proposed by the EU. Combining the 24-recall method with a food propensity questionnaire probably provides the best information.

\section{Intake calculations versus measurement of nutrients in humans: pros and cons. How do they complete each other? What information do we get in both cases?}

This depends on questions need to be answered and the focus of the investigation. The approaches are complementary. Sometimes it is only possible to get data for intake calculations from one of the sources. Furthermore, all aspects of dietary intake cannot be obtained from HBM data, portion sizes is one example. On the other hand, there are examples of biomarkers which give more information than questionnaires; measurements of iodine and sodium in urine are two of these.

It is unethical to carry out large studies that are not well planned. It is necessary to use the data in an optimal way and if it is possible, do follow-ups, in order to make the data more valuable. 


\subsubsection{Group 3 “Steps toward harmonization"}

Participants: Cathrine Thomsen, Norwegian Institute of Public Health (chair); Anne Lagerqvist, National Food Agency, Sweden (notes/report); Milena Horvat, Dept. of Environmental Sciences, Jožef Stefan Institute, Slovenia; Dominique Aerts, Federal Public Service Health, Belgium; Antonia Calafat, National Center for Environmental Health of the Centers for Disease Control and Prevention (CDC), USA; Andrey Egorov, Environmental Health Information System, WHO; Julie Yome, Health Canada; Natalia Kotova, National Food Agency, Sweden; Britta Hedlund, Swedish Environmental Protection Agency.

\section{Propose and motivate five biomarkers which you believe the most important in harmonized HBM programs. Try to include biomarkers of nutrition and/or health status. Discuss also possibility to use "new" biomarkers and/or techniques (emerging risks, exposome, metabolomics etc). How could Nordic countries benefit from collaboration?}

It is difficult to name five specific compounds; it should rather be groups of compounds. These would be: natural toxins, EDC, POPs and metals. Although groups on their own, both the latter include chemicals with endocrine disrupting properties. This choice also depends on what the issue is, i.e. either consumer safety, reduction of exposure or an overview of the population. Biomarkers of nutrition with high importance would be vitamin D, iron (ferritin), magnesium and selenium. If magnesium levels are low, one absorbs other metals such as mercury and lead more easily. This is also true for low levels of iron which gives increased absorption of cadmium. Measurement of selenium levels is important here in Scandinavia because of the low trace levels in the environment. Other parameters of importance are body composition (fat percentage, since BMI is not sufficient) and immunological status (allergies etc).

Cadmium, lead, mercury and arsenic can all be measured in one analysis from $0.5 \mathrm{ml}$ blood compared to urine where more sample volume is needed. There is also need to measure nutritional status to adjust for those parameters which might influence the other biomarkers, protective enzymes for example. Nutritional biomarkers are easy to report to participants since they are relatively simple to interpret.

The volumes of collected samples for biobanking need to be considered carefully at startup. The most important contaminant groups should be analyzed shortly after sampling and as much sample volume as possible should be stored for future needs. Data could be shared between the Nordic countries, so that a study of a particular contaminant 
done, for example, in Norway might make it unnecessary to do the same in Sweden. But in some settings there might be differences between countries as well as between certain groups, for example children and adults. Furthermore, vulnerable groups also need focus.

If well harmonized, HBM data can be summarized or pooled between countries which might help when trying to find heavily exposed subfractions of the population. Although, there has to be caution to ensure that the higher exposures are not false due to discrepancies in measurement technology if they are performed at different laboratories. Quality assured laboratories which use standardized protocols should be selected to ensure comparability in the Nordic countries. Ideally, all samples for one type of analysis should be done at the same lab. Otherwise, harmonization between different labs takes at least a year to achieve. Follow-ups and temporal trends also need harmonization.

The Norwegian Scientific Committee for Food Safety does broad risk assessments based on data available from WHO and EFSA. This committee also makes specific assessments for Norwegian issues to apply on local settings.

Action is needed on policy at governmental level in order to prevent problems related to contaminants in food and environment. It is not enough that the individual consumers make informed choices.

Other questions which arose include:

- Are there some common stressors/contaminants which are more important to certain groups of the population?

- Are upcoming or classic parameters to be measured? For example PFAS or phtalates and their substitutes; mycotoxins, mercury and lead.

- Out of the trace elements, which are the most important?

- There is usually less participation from men than women. How to increase their participation?

\section{What are the missing data in HBM today for risk- and/or benefit assessment? Motivate if there are needs and ways for collaboration between countries}

Food traceability is lacking or incomplete. It is of interest to know from where a particular chemical found in HBM originates. If the traceability of food could be increased, it would be easier to find the source of foodborne contaminants.

Collaboration is an advantage in most cases, the Nordic countries would benefit from doing more projects together. We have similar ways 
of living which means that data from one Nordic country might be useful in another. But, if we are to engage in more collaboration, standard laboratories for different types of analyses should be selected, to assure maintained measurement quality of food- and human samples. Consent for shipping of samples to standard labs is not required within EU/EES. For collaboration to be effective, harmonization of HBM in the Nordic countries is crucial.

The specifics important for collaboration and harmonization were identified to be:

- Common goals.

- Decisions on how to achieve optimal harmonization.

- Funding and political decisions.

- Potential.

- Effectivity and proper choices.

Some additional questions which arose were:

- The biobanks are important. How to improve the use of biobanks in HBM programs?

- What parameters to measure in the future?

- How to assess and work with, for example, nanoparticles?

3. How to overcome problems to involve representative cohorts (number of participants, age, social status, immigrants etc) and ethics (eks. not to be too vague)? Is it motivated to aim for joint sample collection within cohorts for specific diseases and cohorts for environmental monitoring?

Quality assurance is important especially in the context of harmonization and collection of information. The number of participants does not need to be harmonized, but the sampling approach is more important. The sampling procedure needs to be the same if the samples are to be comparable. In general, it is not that difficult to succeed with harmonization. Selection of subjects and construction of questionnaires are harmonized within Europe. Collaboration between environmental monitoring and HBM within cohorts for specific diseases often proves to be cost effective and is motivated for this reason.

Taking demographics into consideration at the stage of study design is crucial. Comparable situations should be used in different countries when selecting participants (i.e. not select subjects from a city in one 
country and from rural areas in another). In US it is custom to ask "How do you consider yourself - Hispanic white, Non-Hispanic white, African American?" etc, and it does not offend people. In Europe, it is not politically correct to ask about ethnicity and/or religion. It might be enough to ask for country of origin and if the participant belongs to the 1st or 2nd generation immigrants (note that the 2 nd generation is likely to answer the country they are born and live in).

Focus is needed for vulnerable groups and new immigrants who might come with different exposure backgrounds. Specific programs are needed for the immigrant population since they do not participate spontaneously to the same degree. Focus groups are needed to reach them. One possibility could be to determine which group that is preferred and do a small pilot study to see how to attract them to participate. A small reward is one way which might make it easier to attract participants. Contact can be made through certain groups: sports teams, language courses etc. Someone who knows the language and culture could do the recruitment. For example due to traditions some groups might have certain restrictions; some do not want to donate hair, others do not want to answer personal questions etc. Other individuals might have fled from an oppressive system and they do not want to be in governmental registers more than needed. It is still important to ensure integration of the immigrant population into the studies and new strategies might help to ensure their willingness to participate.

As wide sampling as possible should be done to allow for procedures and analysis to be performed at least 50 years later. Sampling from parts of the populations might be required for analysis of specific diseases. Development of technologies makes biobanks very useful and allowing for subsequent analysis of a certain parameter which can be retraced through time. An inventory of existing biobanks is needed to have the information collected. However, it is not ethical to ask for much more sample volume than what is needed for a particular study. It was pointed out that it seems to be the amount of tubes which is important for the participants, not the total amount of blood.

Joint sampling can be done in NHANES to allow for measurement of some extra parameters. This extra sampling and analysis can be done each year if funding exists. For example, during one year, a project concerning thyroid research had some extra allowance of samples in NHANES. 


\section{How is the HBM data used today and what need of data are foreseen in the near future? Take also into account dietary data/surveys}

The use is very varied today and many different types of projects exist. For example, there is a large difference if weight will be put to each individual in the study or if the aim is to cover the whole population. It is more useful with general cohorts.

The data will probably be used to assess health outcomes and epidemiology to satisfy variable interests. Dietary information is very important. Moreover, studies on human health which are already conducted can give a lot of useful information, also when designing a new study. There are such completed studies in the Nordic countries and we should use the data collected within these projects.

Reference value production compared to measurements in specific groups was discussed. It was concluded that sampling of subpopulations such as immigrants from different countries and rural versus urban areas might be required to get the full picture of the exposure or nutritional status in the population. Pooling of information from different countries gives an average value but it will not be exact.

All stages of the projects must be well documented, from planning to standard operating procedures and statistics in order to make the harmonization work. One institution should be setting the standards and if collaborators exist, the standards need to be written down and cautiously followed by the participants. In the projects COPHES and DEMOCOPHES, the same questionnaire was used for several countries in the EU with small adaptations if needed for certain areas. In the EU project HELIX there are 6 cohorts in different countries. The questionnaire had a basic core but questions could be added for each cohort. The participants should not be burdened by unnecessary questions and the personnel on the field need to be familiar with the questionnaire. The personnel handling the questionnaires should also know how the questions are supposed to be interpreted and what each question actually addresses. Another important factor to document is how samples are taken and stored.

New strategies have to be built on those which already exist. If the proper analysis methods do not exist yet, it is impossible to know if the samples need treatment in a particular way to be useful and subsequent analysis might therefore be impossible. It is difficult to predict what should be done later when establishing a biobank. 


\subsubsection{Group 4 "HBM as an early warning"}

Participants: Per Ola Darnerud, National Food Agency, Sweden (chair); Elin Boalt, National Food Agency, Sweden (notes/report); Robin Vestergren, Norwegian Institute for Air Research (NILU); Heneli Lamp, Veterinary and Food Board of Estonia; Karin Ljung Björklund, The Public Health Agency of Sweden; Linda Linderholm, Swedish Environmental Protection Agency; Ingvar Bergdahl, Umeå University, Sweden; Marike KolossaGehring, Federal Environmental Agency, Germany; Bodil Hammer Bech, Dept of Public Health, Aarhus University, Denmark.

1. Propose and motivate five biomarkers which you believe might act to monitor "new emerging risks". Are there needs and ways to collaborate between Nordic countries?

New and emerging risks include:

- Plasticizers which are of importance, for example phthalates to which humans are exposed via food contact materials. There are compounds intended as replacements for phthalates but these are not well investigated and could compose an emerging risk. If the production of PVC plastic is reduced, the use of phthalates can be reduced up to $80 \%$. At present, production is instead increasing and toxicological information concerning the replacement compounds is lacking although some of them seem to be bio-accumulating. The exposure of humans to these compounds is in part related to how food is handled with and packed in materials containing plasticizers.

- New flame retardants, for example those containing phosphate which are now replacing the brominated ones, are another group of possible contaminants which should cause concern.

- New use of metals in electronic equipment might be an emerging risk but this might be more of an issue for occupational exposure control.

- The use of silver particles and nanoparticles is increasing, for example in textiles and detergents. The direct toxicity from these is rather low, but avaliable silver is increasing in the environment.

- Pyrrolidone compounds are also of interest. An example is N-methyl2-pyrrolidone (NMP) and the replacement $\mathrm{N}$-ethyl-2-pyrrolidone (NEP) which is a reproductive toxicant ${ }_{2}$ these are found in the general population [64]. The first is present on the candidate list of REACH but might need more regulation. These compounds are used 
in the petrochemical industry as well as for paint removal and surface treatment of textiles.

\section{Which are the ways to improve HBM of "new emerging risks"?}

Non-target screening in environmental and human samples can give the possibility to search for new or unknown contaminants. By use of the candidate list of substances with high concern from REACH, it may be possible to identify new substances to monitor. This requires the candidate list to be updated with better efficiency. Harmonization of labs is also important when analyzing new compounds or biomarkers. Labs focusing on specific compounds might be a fruitful way to address this. For biobanking it is beneficial to ensure that there is permission to use the samples in other countries than the country of collection. Harmonization between methods for sample collection as well as for analytical measurements is highly relevant.

\section{National-wide versus regional HBM: pros. and cons. Motivate if there are needs and ways for collaboration between Nordic countries} In respect to the approach, and feasibility to conduct a study, it is easier in regional studies. However, regional data might be difficult to interpret. A continuous investigation increases the response rate. A local investigation involves a higher response rate. Even in nationwide studies, samples can be taken from specific regions. As an example, in pannational study "Riksmaten", a project conducted by the Swedish NFA [65], rural populations had lower levels of phthalates than the urban ones. In respect to intake of contaminants via food, but with exception for mercury, there is little variation between the European nations. The differences seen tend to depend more on socio-economic factors rather than regional differences, as was seen in DEMOCOPHES.

There are ways for collaboration between the Nordic countries in terms of harmonization of study design and meeting of experts. This enables focus on areas where work is needed and not performed sufficiently elsewhere. Well established collaboration between the Nordic countries is also beneficial for optimal communication between ongoing research projects.

One well-functioning example of Nordic collaboration is the Nordic council of ministers financed Nordic screening group [66]. A collaborative screening is made every year containing samples from the seven included entities and the same lab is used for all analyses the same year. Furthermore, the group has a workshop every second year. The entities which participate are: Denmark, Faroe Islands, Finland, Greenland, Iceland, Norway and Sweden. 


\section{How to improve risk management response to the early warning signals of change to avoid "late lessons"?}

There should be more precaution regarding substitutes and focus should lie on reduction of body burdens via a particular source, for example phthalates via food. The discussion should not be focused on particular chemicals, but instead on the combined exposure which the population continually receives from the many different consumer products and other sources.

\subsubsection{Summary of the discussions}

There are many known compounds which affect the human population in different ways. It is possible to reduce body burdens from a particular source via regulation and active consumer choices, for example exposure to phthalates via food.

Some of the compounds mentioned here were:

- Persistent compounds in general.

- Compounds which impair the development of the fetal brain.

- Phenolic compounds.

- Metals.

- Natural toxins.

- Phthalates.

- Flame retardants.

- Poly- and perfluorinated compounds.

- Pyrrolidines.

- Chlorinated compounds due to the many sources of usage, they are especially important since they constitute substitutes for other compounds.

- Tributyltin (TBT).

- Mycotoxins; DON in particular which has known adverse health effects connected to seasonal trends and climate change.

Nutritional markers were also mentioned as follows

- vitamin D

- magnesium

- selenium 
- iodine

- sodium

- potassium

- iron (ferritin)

- folates

- vitamin C

- antioxidants in general.

Iodine intake is linked to intake of milk and iodized salt, which is decreasing in the general population. Due to this fact, possibilities of conducting pilot study measuring iodine as a collaboration between the Nordic countries was discussed and should be investigated. ${ }^{2}$

It is also important to measure weight and height as opposed to having those parameters as self-reported. Other important parameters are body composition (fat percentage), allergies and other types of immunological status.

The recruitment of participants is one of the challenges to overcome. The recruitment might be easier in specific groups such as blood donors, persons in military service, pregnant women and their partners. But successful recruitment also depends on the focus of the study. If recruiting within a very narrow group, the results might not be applicable to the population as a whole. Socio-economical background must be known to account for correction. There is a problem with successful recruitment of participants from immigrant groups. Experts from immigrant groups could be focused on including these groups. Those conducting the questionnaires should know the aim of the study. Toxicity data can concern personal risk or risk of the population. Repeated sampling is always valuable.

Nordic collaboration might make HBM more efficient. Higher number of participants gives better power and is more cost efficient. Furthermore, in order to share data, the planning, procedure and data need to be harmonized which requires collaboration. Increased collaboration between the Nordic countries would give a stronger case towards policy makers. The Nordic countries are relatively small which increases the benefit from extensive collaboration and harmonization. The Nordic countries also have well managed national registers that can be used. Combination of data and registers provide increased quality and reliability. Harmonization of study design and meeting of experts enables focus 
on areas where work is needed and not performed sufficiently elsewhere. Overall, collaboration between countries increases the power of the HBM programs.

The importance of well-planned studies was addressed. The initial planning is important both for cost effectiveness as well as for avoiding collection of unnecessary data that is not used. Pooling of data from different areas, gives an overview of a larger area, but the results are not that exact. Several studies on health factors which are already available can be used to design new studies. It is easier to conduct a study in regional settings, but regional data might be difficult to interpret. But, even in nationwide studies, samples are taken from specific regions. In some projects, more socio-economical differences rather than regional differences were found in the population. A continuous investigation increases the response rate from possible participants, as does a regional investigation.

Increased precaution is necessary regarding substitutes to problematic chemicals. The discussion should not be focused on particular chemicals, but instead on the combined exposure which the population continually receives from the many different consumer products and other sources. It is important that the discussion is lifted from the detail of regulation for specific compounds to instead address regulation of compound groups and combined exposures. 



\section{Conclusions}

It was agreed that the Nordic collaborative efforts should be further developed within the area of HBM and that there would, unquestionably, be benefits from this in terms of harmonization and thus comparability between different studies. This would not only give an increased potential for impact on policymaking but also an increase in information which can positively influence public health, for example through informed choices by consumers.

Continuous development of methods related to HBM is needed since there are always new contaminants and parameters which require assessment. One crucial question is how to properly address and evaluate emerging risks. Furthermore, many of the most reactive compounds to which we are exposed, are by nature difficult to measure. Analysis of adducts to proteins and DNA is therefore important since the most reactive compounds disappear quickly into these conformations and thus are not measurable on their own. In addition, one more challenge lies in the proper assessment of mixture effects. The population is exposed to a wide variety of xenobiotic compounds and naturally occurring substances. For this reason, it is not possible to determine a safe exposure level for each specific compound without taking the interaction between these compounds into account. Due to this complexity, the classic risk estimation methods are in need of substantial revision.

Another factor which is of continuous interest is monitoring of specific contaminated sites. In the Nordic countries these include former factory sites and garbage dump sites with related contamination of the surrounding environment. There is also an emerging problem concerning contamination of drinking water by PFAS originating from firefighting foam used at airports for training purposes.

Furthermore, health- and nutritional status are also important as they might influence the reaction to exposure to xenobiotic compounds. Specific deficiencies and/or deviations in health biomarkers (for example hormonal levels or certain genotypes for important enzymes) are present in certain groups of the population and this needs surveillance in order to decrease the risks of adverse effects. Also, individual choices which might result in decreased intake of micronutrients comprise a general concern and need to be assessed on population level. 
The regulation which is present under the European chemical legislation, REACH, is not enough to ensure the safety of the population when it comes to exposures to industrial chemicals. REACH is essentially a beneficial tool but it lacks the swiftness and determination needed in this area. The legislation and regulation within the area needs to be efficient and ensure protection of the population from undesired exposures. Although somewhat effective, this protection cannot rely on informed choices by the individual. Revision of the legislation and risk management is vital to ensure the safety of the population.

It was agreed that it is beneficial to have an inventory of biobanks which is shared between the Nordic countries (www.bbmri.se [67]). For the future, when building large national biobanks, all Nordic countries should ideally be involved. The standard procedures for biobanking cannot change every year but have to be set and continued with. Different projects concerning biobanking were mentioned: a) EXPOsOMICS, HELIX and HEALS - EU-projects which dive into existing biobanks; b) the "human miljøbiobank Norge" project that has received permission to enter the national biobank MoBa (Norwegian Mother and Child Cohort). In $\mathrm{MoBa}$, approximately 100,000 pregnant women, babies and their fathers donated samples between 1999 and 2008; a second round of sampling of the same subjects is presently under planning. The initial idea was to start from scratch but this would involve too much effort and funding, hence, it was more strategic to use the existing cohort. It is common practice to use biobanks this way, which is very beneficial and the way biobanks are supposed to be used.

There are crucial moments when using existing biobanks, and an appropriate motivation for the study should be required. Larger blood volumes for banking are almost always desired but to increase the amount of blood collected from the participants can be problematic. Not much more sample volume than what is needed for a particular study is ethical to ask for. For the participants, it seems to be the amount of tubes with blood samples which is important, not the total amount of blood. This indicates that it might be easier to increase the amount of blood collected per tube compared to increasing the amount of tubes. Furthermore, there is a large amount of samples accumulated by research groups and companies. Knowledge of these would be useful as a complement to biobanks. One problem is that samples which are already collected in biobanks might lack certain information which is needed together with subsequent analyses. An example is insufficient detail of the dietary information collected in connection with biobanking. Moreover, guidelines 
regarding harmonization are needed (sampling procedure, amount and storage conditions of tubes, documentation etc.).

In general, this meeting revealed interest and need for future collaboration between the Nordic countries concerning HBM for collection of dietary data as well as for monitoring of contaminant and nutrient levels in consumers. Harmonization concerning the same topics is also desired. 



\section{Sammanfattning}

Livsmedelsverket anordnade i maj 2014 ett seminarium med titeln "Human biomonitoring as a tool in policy making towards consumer safety." Seminariet hölls under två dagar i Stockholm och handlade om biomonitorering i människa och dess potential för policyskapande. Mötet finansierades av Nordiska ministerrådet samt den svenska Myndigheten för samhällsskydd och beredskap. Syftet var att sprida information om existerande biomonitoreringsprojekt samt att utreda ifall det finns potential och intresse för ett utökat nordiskt samarbete på området.

Experter från Livsmedelsverket, andra svenska organisationer, övriga nordiska länder samt Europa, USA och Kanada var närvarande. En överblick av existerande stora biomonitoreringsprojekt, metodologiska utmaningar, samt aktuella problem med exponering för oönskade ämnen med fokus på kemikalier gavs under den första dagen. Dessa presentationer följdes av en generell diskussion om biomonitorering och konsumenters exponering för kontaminanter i mat och miljö. Under dag två genomfördes organiserade diskussioner med olika teman rörande biomonitorering i människa som ett verktyg i policyskapande. Några exempel var åtgärder för minskad exponering för farliga kemikalier samt berikning av livsmedel med näringsämnen som populationens konsumtion inte täcker.

Efter seminariet kunde slutsatsen dras att mer nordiskt samarbete och harmonisering inom området är att önska. Detta gäller inte bara harmonisering av analyser av prover utan också av andra parametrar såsom själva provtagningen, hanteringen mellan provtagning och analys samt långtidsförvaring av prover och datainsamling. Mer samarbete och harmonisering av studier som utförs i de nordiska länderna skulle också ge bättre grund för policyskapande i Norden och EU och därmed bidra till positiva folkhälsoeffekter. 



\section{Abbreviations}

\begin{tabular}{|c|c|}
\hline AMAP & Arctic Monitoring and Assessment Program \\
\hline BDE & Brominated Diphenyl Ether \\
\hline BMD & Bench Mark Dose \\
\hline BTEX & Benzene, Toluene, Ethylbenzene, and Xylenes \\
\hline $\mathrm{CDC}$ & Centers for Disease Control and Prevention \\
\hline COPHES & Consortium to Perform Human Biomonitoring on a European Scale \\
\hline DBP & DiButyl Phthalate \\
\hline DDT & DichloroDiphenylTrichloroethane \\
\hline DEHP & Di-2-EthylHexyl Phthalate \\
\hline DEMOCOPHES & DEMOnstration of a study to Coordinate and Perform Human biomonitoring on an European Scale \\
\hline DEP & DiEthyl Phthalate \\
\hline DiBP & DiisoButyl Phthalate \\
\hline DINCH & DiisoNonyl CycloHexane \\
\hline DON & DeOxyNivalenol (Vomitoxin) \\
\hline DPHP & DiPropylHeptyl Phthalate \\
\hline DQO & Data Quality Objects \\
\hline ECEH & WHO European Centre for Environment and Health \\
\hline EDCS & Endocrine Disrupting Chemicals \\
\hline ENHIS & ENvironmental Health Information System \\
\hline GEF & Global Environment Facility \\
\hline GMOS & Global Mercury Observation System \\
\hline HBM & Human BioMonitoring \\
\hline MBP & MonoButyl Phtalate \\
\hline MiBP & MonoisoButyl Phthalate \\
\hline MSB & Swedish Civil Contingencies Agency \\
\hline NEP & N-Ethyl-2-pyrrolidone \\
\hline NFA & National Food Agency (Sweden) \\
\hline NHANES & National Health And Nutrition Examination Survey \\
\hline NKMT & Nordic Working Group for Diet, Food \& Toxicology \\
\hline NMP & N-Methyl-2-pyrrolidone \\
\hline NMR & Nordiska MinisterRådet \\
\hline NOAEL & No Observed Adverse Effect Level \\
\hline OECD & Organisation for Economic Co-operation and Development \\
\hline $\mathrm{PAH}$ & Polycyclic Aromatic Hydrocarbons \\
\hline PCB & PolyChlorinated Biphenyl \\
\hline PFAA & PerFluorinated Alkyl Acids \\
\hline PFAS & PerFluorinated Alkyl Substances \\
\hline PFBS & PerFluoroButane Sulfonate \\
\hline PFHxS & PerFluoroHexane Sulfonate \\
\hline PFOA & PerFluorooctanoic Acid \\
\hline PFOS & PerFluorooctane sulfonate \\
\hline PHIME & Public Health Impact of long-term low-level Mixed Element Exposure in susceptible population strata \\
\hline POPs & Persistent Organic Pollutants \\
\hline REACH & Registration, Evaluation, Authorization and restriction of Chemicals \\
\hline SOP & Standard Operating Procedure \\
\hline TВT & TriButyl Tin \\
\hline TDI & Tolerable Daily Intake \\
\hline UNEP & United Nations Environment Program \\
\hline
\end{tabular}





\section{References}

1. National Health and Nutrition Examination Survey. Centers for Disease Control and Prevention; Available from: http://www.cdc.gov/nchs/nhanes/about_nhanes.htm

2. Nutrition monitoring in the United States: The directory of Federal and State nutrition monitoring and related research activities., K. Bialostosky, Editor. 2000, Interagency Board for Nutrition Monitoring and Related Research.: Hyattsville, Maryland.

3. National Health and Nutrition Examination Survey; What's New. Centers for Disease Control and Prevention; Available from: http://www.cdc.gov/nchs/ nhanes/new_nhanes.htm

4. Centers for Disease Control and Prevention. Available from: http://www.cdc.gov/

5. National Report on Human Exposure to Environmental Chemicals Centers for Disease Control and Prevention; Available from: http://www.cdc.gov/exposurereport/

6. Mobile Exam Center Components Descriptions, http://www.cdc.gov/nchs/data/ nhanes/nhanes_09_10/meccomp_f.pdf Editor: Centers for Disease Control and Prevention.

7. National Health and Nutrition Examination Survey 1999-2012 Survey Content Brochure, in http://www.cdc.gov/nchs/data/nhanes/survey_content_99_12.pdf Centers for Disease Control and Prevention.

8. National Health and Nutrition Examination Survey; Questionnaires, Datasets, and Related Documentation. Centers for Disease Control and Prevention; Available from: http://www.cdc.gov/nchs/nhanes/nhanes_questionnaires.htm

9. Second National Report on Biochemical Indicators of Diet and Nutrition in the U.S. Population, in http://www.cdc.gov/nutritionreport/2012, Centers for Disease Control and Prevention.

10. National Health and Nutrition Examination Survey; Welcome NHANES Participants. Centers for Disease Control and Prevention; Available from: http://www.cdc.gov/nchs/nhanes/participant.htm

11. Lead: What Do Parents Need to Know to Protect Their Children? Centers for Disease Control and Prevention; Available from: http://www.cdc.gov/nceh/ lead/ACCLPP/blood_lead_levels.htm

12. National Report on Human Exposure to Environmental Chemicals; Chemical Selection. Centers for Disease Control and Prevention; Available from: http://www.cdc.gov/exposurereport/chemical_selection.html

13. Calafat, A.M., et al., Urinary concentrations of triclosan in the U.S. population: 2003-2004. Environ Health Perspect, 2008. 116(3): p. 303-7.

14. Environmental Protection Agency. Available from: http://www.epa.gov/oppsrrd1/REDs/factsheets/triclosan_fs.htm

15. Calafat, A.M., et al., Urinary concentrations of four parabens in the U.S. population: NHANES 2005-2006. Environ Health Perspect, 2010. 118(5): p. 679-85.

16. Calafat, A.M., et al., Concentrations of the sunscreen agent benzophenone- 3 in residents of the United States: National Health and Nutrition Examination Survey 2003-2004. Environ Health Perspect, 2008. 116(7): p. 893-7. 
17. Pirkle, J.L., et al., Trends in the exposure of nonsmokers in the U.S. population to secondhand smoke: 1988-2002. Environ Health Perspect, 2006. 114(6): p. 853-8.

18. Kato, K., et al., Trends in exposure to polyfluoroalkyl chemicals in the U.S.

Population: 1999-2008. Environ Sci Technol, 2011. 45(19): p. 8037-45.

19. Prevedouros, K., et al., Sources, fate and transport of perfluorocarboxylates. Environ Sci Technol, 2006. 40(1): p. 32-44.

20. Zota, A.R., A.M. Calafat, and T.J. Woodruff, Temporal trends in phthalate exposures: findings from the National Health and Nutrition Examination Survey, 2001-2010. Environ Health Perspect, 2014. 122(3): p. 235-41.

21. Asacol HD meselamine. Available from: http://www.asacolhd.com/

22. European Chemicals Agency; REACH. Available from: http://echa.europa.eu/web/ guest/regulations/reach/

23. CDC; National Health and Nutrition Examination Survey. Centers for Disease Control and Prevention; Available from: http://www.cdc.gov/nchs/nhanes.htm

24. Schulz, C., et al., The German Human Biomonitoring Commission. Int J Hyg Environ Health, 2007. 210(3-4): p. 373-82.

25. Schulz, C., et al., Update of the reference and HBM values derived by the German Human Biomonitoring Commission. Int J Hyg Environ Health, 2011. 215(1): p. 26-35.

26. HBM-commission, Grundsatzpapier zur Ableitung von HBM-Werten.

Bundesgesundheitsblatt Gesundheitsforschung Gesundheitsschutz, 2014.

27. Biomonitoring methods. The MAK collection; Available from: http://www.wileyvch.de/publish/en/books/ISBN3-527-33438-6/

28. The MAK collection. Available from: http://www.wiley-vch.de/books/info/mak/ collection.php

29. HBM commission. Available from: http://www.umweltbundesamt.de/en/ topics/health/commissions-working-groups/human-biomonitoring-commission

30. Umwelt Bundessamt. Available from: http://www.umweltbundesamt.de/en

31. COPHES. Available from: http://www.eu-hbm.info/cophes

32. DEMOCOPHES. Available from: http://www.eu-hbm.info/democophes

33. Human Biomonitoring Europe. Available from: http://www.eu-hbm.info/

34. Global mercury Observation System (GMOS). Available from: http://www.gmos.eu/

35. Public Health Impact of long-term, low-level Mixed Element Exposure in susceptible population strata (PHIME). Available from: http://www.med.lu.se/labmedlund/ amm/forskning/haelsorisker_av_metaller/phime

36. Joas, R., et al., Harmonised human biomonitoring in Europe: activities towards an EU HBM framework. Int J Hyg Environ Health, 2012. 215(2): p. 172-5.

37. World Health Organization (WHO) Regional Office for Europe. Parma Declaration on Environment and Health. Avaliable from: http://www.euro.who.int/_data/ assets/pdf_file/0011/78608/E93618.pdf?ua=1

38. DEMOCOPHES - Human Biomonitoring on a European Scale. Press kit. Available from: http://www.eu-hbm.info/euresult/media-corner/press-kit

39. WHO Regional Office for Europe. Biomonitoring-based indicators of exposure to chemical pollutants. Report of a meeting. Catania, Italy, 2012. Available from: http://www.euro.who.int/_data/assets/pdf_file/0004/170734/e96640.pdf?ua=1

40. Minamata Convention on Mercury. Text and Annexes. Available from:

http://www.mercuryconvention.org/Portals/11/documents/Booklets/Minamata \%20Convention\%20on\%20Mercury_booklet_English.pdf 
41. Grandjean, P. Chemical Brain Drain. Available from: http://braindrain.dk/

42. European Environment Agency. Available from: http://www.eea.europa.eu/

43. Late lessons from early warnings: science, precaution, innovation, in http://www.eea.europa.eu/publications/late-lessons-2. 2013, European Environment Agency.

44. Grandjean, P. and P.J. Landrigan, Developmental neurotoxicity of industrial chemicals. Lancet, 2006. 368(9553): p. 2167-78.

45. Grandjean, P. and P.J. Landrigan, Neurobehavioural effects of developmental toxicity. Lancet Neurol, 2014. 13(3): p. 330-8.

46. FETOTOX (1). Available from: http://fetotox.au.dk/the-fetotox-birthcohorts/aarhus-birth-cohort-biobank-abcb/

47. Eriksson, J.G., et al., Early growth and coronary heart disease in later life: longitudinal study. BMJ, 2001. 322(7292): p. 949-53.

48. FETOTOX (2). Available from: http://fetotox.au.dk/the-fetotox-birth-cohorts/

49. AMAP. Available from: http://www.amap.no/

50. Bertelsen, R.J., et al., Probiotic milk consumption in pregnancy and infancy and subsequent childhood allergic diseases. J Allergy Clin Immunol, 2014. 133(1): p. 165-71 e1-8.

51. UNEP/AMAP, Climate Change and POPs: Predicting the Impacts, in The UNEP/AMAP Expert Group. . 2011, Secretariat of the Stockholm Convention, Geneva.: http://www.amap.no/documents/doc/climate-change-and-popspredicting-the-impacts $/ 753$

52. ArcRisk. Available from: http://www.arcrisk.eu/

53. Lignell, S., et al., Levels of persistent halogenated organic pollutants (POP) in mother's milk from first-time mothers in Uppsala, Sweden - results from 2008/2010 and temporal trends 1996-2010. 2012, Swedish National Food Agency Uppsala.

54. Bjornberg, K.A., et al., Methyl mercury exposure in Swedish women with high fish consumption. Sci Total Environ, 2005. 341(1-3): p. 45-52.

55. Tornkvist, A., et al., $P C D D / F, P C B, P B D E, H B C D$ and chlorinated pesticides in a Swedish market basket from 2005--levels and dietary intake estimations. Chemosphere, 2011. 83(2): p. 193-9.

56. Glynn, A., et al., Perfluorinated alkyl acids in blood serum from primiparous women in Sweden: serial sampling during pregnancy and nursing, and temporal trends 19962010. Environ Sci Technol, 2012. 46(16): p. 9071-9.

57. Swedish National Food Agency. Available from: http://www.slv.se/sv/grupp1/Dricksvatten/Dricksvattenkvalitet/Perfluoreradealkylsyror/Riskhanteringsatgard-PFAA/

58. Kartläggning av PFAA i råvatten och dricksvatten, april 2014. Swedish National food Agency 2014; Available from: http://www.slv.se/upload/dokument/ rapporter/dricksvatten/Rapport-kartlaggning-PFAA-i-ravatten-ochdricksvatten.pdf

59. Health Canada (1). Available from: http://www.hc-sc.gc.ca/index-eng.php

60. Health Canada (2). Available from: http://www.hc-sc.gc.ca/ewh-semt/ contaminants/human-humaine/chms-ecms-eng.php

61. Government of Canada. Available from: http://www.science.gc.ca/ default.asp?lang=En\&n=7A463DBA-1

62. Health Canada (3). Available from: http://www.hc-sc.gc.ca/ewh-semt/ contaminants/human-humaine/mirec-eng.php 
63. First nations biomonitoring initiative, in http://www.afn.ca/uploads/files/ afn_fnbi_en_-_2013-06-26.pdf 2013, The Assembly of First Nations (AFN).

64. Chemicals known to the state to cause cancer or reproductive toxicity, in http://www.oehha.ca.gov/prop65/prop65_list/files/P65single091009.pd. 2009, State of California: Environmental protection agency, Office of environmental health hazard assessment.

65. Riksmaten, Swedish national Food Agency. Available from: http://www.slv.se/ grupp1/Mat-och-naring/Matvanor---undersokningar/

66. Nordic screening group. Available from: http://nordicscreening.org/

67. BioBanking and Molecular Resource Infrastructure of Sweden. Available from: http://www.bbmri.se/ 


\section{Appendix I: Program}

Human biomonitoring as a tool in policy making towards consumer safety

May 22nd-23rd 2014, Stockholm City Conference Centre, Norra Latin, Sweden.

\section{May 22nd: Presentations and discussions}

The first seminar day is focused on international experiences of human biomonitoring (HBM) as an effective tool for tracing consumers' exposure to hazardous substances. Moreover, the potential of HBM as an early warning system in support of policy making to prevent and/or minimize health risks is discussed.

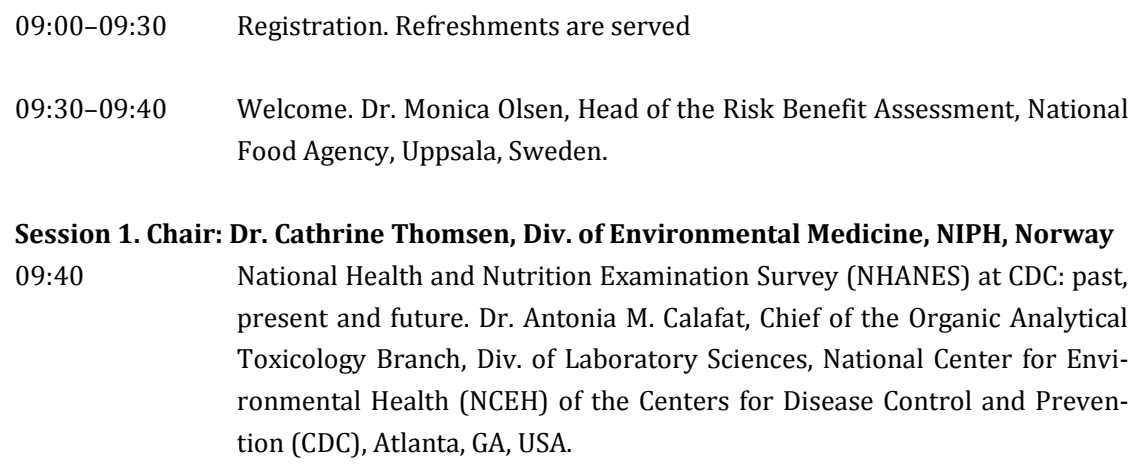

Session 1. Chair: Dr. Cathrine Thomsen, Div. of Environmental Medicine, NIPH, Norway 09:40 National Health and Nutrition Examination Survey (NHANES) at CDC: past, present and future. Dr. Antonia M. Calafat, Chief of the Organic Analytical Toxicology Branch, Div. of Laboratory Sciences, National Center for Environmental Health (NCEH) of the Centers for Disease Control and Prevention (CDC), Atlanta, GA, USA.

10:30 HBM-Commission at Federal Environment Agency: exposure \& health. Dr Marike Kolossa-Gehring, Dept of Environmental Hygiene, Section Toxicology, Health Related Environmental Monitoring /Umweltbundesamt (Federal Environment Agency), Germany.

11:00-11.15 Break

11:15 Comparability of European data in human biomonitoring. Prof. Milena Horvat, Head of the Dept of Environmental Sciences, Jožef Stefan Institute, Ljubljana, Slovenia.

11:45-13:00 Lunch

Session 2. Chair: Dr. Marika Berglund, Inst. of Environmental Medicine, Karolinska Institute drey Egorov, Environmental Health Information System (ENHIS), World Health Organization. 

Philippe Grandjean, Dept of Environmental Health / Harvard School of Public Health; Head of Dept. of Environmental Medicine / University of Southern Denmark.

14:00 Biobanking: preserving samples for future research - example from a Danish Biobank. Ass. Prof. Bodil Hammer Bech, Dept of Public Health, Institute of Epidemiology and Social Medicine, Aarhus University, Denmark.

14:30-15:00 Coffee break

15:00 Biomonitoring in scarcely populated areas. Prof. Jon Øyvind Odland, Dept for Public Health, the Arctic University of Norway.

Use of HBM in risk assessment for food safety. Ass. Prof. Anders Glynn, Risk Benefit Assessment Unit, National Food Agency, Sweden.

16:00-17:00 From human biomonitoring to regulations - lessons learned. Debate. Moderator: Dr. Leif Busk, Scientific Expert, National Food Agency, Sweden.

\section{May 23rd: Interactive workshop}

This day is primarily directed towards one of the working groups of the Nordic Council of Ministers - the Nordic Working Group for Diet, Food \& Toxicology (NKMT) - as well as other Nordic partners working with HBM and/or food safety related topics. The aim is to actively discuss a basis for Nordic collaboration within biomonitoring of nutrients and contaminants in biological samples from humans.

\begin{tabular}{|c|c|}
\hline 09:00-09:20 & Reflections from the first meeting day. \\
\hline 09:20-10:00 & $\begin{array}{l}\text { Biomonitoring of nutrients and contaminants in consumers - proposals } \\
\text { for Nordic network. Discussion, Part } 1 .\end{array}$ \\
\hline 10:00-10:20 & Coffee break \\
\hline 10:20-11:15 & $\begin{array}{l}\text { Biomonitoring of nutrients and contaminants in consumers - proposals } \\
\text { for Nordic network. Discussion, Part } 2 .\end{array}$ \\
\hline 11:15-12:00 & Report from discussions, summary, conclusions. \\
\hline 12:00-13:00 & Lunch \& departure \\
\hline
\end{tabular}




\section{Appendix II: Participant list}

\begin{tabular}{|c|c|c|c|}
\hline Participants & & Organzation/Company & Country \\
\hline Aasa & Jenny & Inst. for Environmental Chemistry, Stockholm University & Sweden \\
\hline Abramsson Zetterberg & Lilianne & Swedish National Food Agency & Sweden \\
\hline Aerts & Dominique & Federal Public Service Health, Food Chain Safety \& Environment & Belgium \\
\hline Andersen & Ingrid Stavenes & Norwegian Food Safety Authority & Norway \\
\hline Bech Hammer & Bodil & Dept of Public Health, Aarhus University & Denmark \\
\hline Bergdahl & Ingvar & Dept. of Biobank Research, Umeå Universit & Sweden \\
\hline Berglund & Marika & IMM, Karolinska Institutet & Sweden \\
\hline Birgisdóttir & Bryndís Eva & $\begin{array}{l}\text { Unit for Nutrition Research, Landspitali University Hospital and } \\
\text { University of Iceland }\end{array}$ & Iceland \\
\hline Bjermo & Helena & $\begin{array}{l}\text { Centre for epidemiology and community medicine, Stockholm } \\
\text { county council }\end{array}$ & Sweden \\
\hline Boalt & Elin & Swedish National Food Agency & Sweden \\
\hline Busk & Leif & Swedish National Food Agency & Sweden \\
\hline Calafat & Antonia & $\begin{array}{l}\text { National Center for Environmental Health of the Centers for Disease } \\
\text { Control and Prevention (CDC) }\end{array}$ & USA \\
\hline Darnerud & Per Ola & Swedish National Food Agency & Sweden \\
\hline Egorov & Andrey & Environmental Health Information System, World Health Organization & Germany \\
\hline Erlund & Iris & National Institute for Health and Welfare & Finland \\
\hline Glynn & Anders & Swedish National Food Agency & Sweden \\
\hline Grandjean & Philippe & $\begin{array}{l}\text { Dept. of Environmental Health, Harvard University, USA \& Environ- } \\
\text { mental Medicine, University of Southern Denmark }\end{array}$ & Denmark \\
\hline Gyllenhammar & Irina & Swedish National Food Agency & Sweden \\
\hline Halldorsson & Thorhallur Ingi & University of Iceland & Iceland \\
\hline Hedlund & Britta & Swedish Environmental Protection Agency & Sweden \\
\hline Holm & Mette & Ministry for Food, Agriculture and Fisheries of Denmark & Danmark \\
\hline Horvat & Milena & Dept. of Environmental Sciences, Jožef Stefan Institute & Slovenia \\
\hline Härnwall & Eva-Lena & MBW, Stockholm University & Sweden \\
\hline Jenssen & Dag & MBW, Stockholm University & Sweden \\
\hline Johansson & Niklas & Melica Biologkonsult & Sweden \\
\hline Knudsen & Lisbeth $\mathrm{E}$. & University of Copenhagen & Denmark \\
\hline Koivisto & Pertti & Finnish Food Safety Authority, Evira & Finland \\
\hline Kolossa-Gehring & Marike & Federal Environmental Agency & Germany \\
\hline Kotova & Natalia & Swedish National Food Agency & Sweden \\
\hline Lagerqvist & Anne & Swedish National Food Agency & Sweden \\
\hline Lamp & Heneli & Veterinary and Food Board of Estonia & Estonia \\
\hline Lignell & Sanna & Swedish National Food Agency & Sweden \\
\hline Lillegaard & Inger Therese & The Norwegian Scientific Committee for Food Safety & Norway \\
\hline Linderholm & Linda & Swedish Environmental Protection Agency & Sweden \\
\hline Lindh & Christian & Lund University & Sweden \\
\hline Lindroos & Anna Karin & Swedish National Food Agency & Sweden \\
\hline Ljung Björklund & Karin & The Public Health Agency of Sweden & Sweden \\
\hline
\end{tabular}




\begin{tabular}{|c|c|c|c|}
\hline \multicolumn{2}{|l|}{ Participants } & \multirow{2}{*}{$\begin{array}{l}\text { Organzation/Company } \\
\text { Norwegian Institute of Public Health }\end{array}$} & \multirow{2}{*}{$\begin{array}{l}\text { Country } \\
\text { Norway }\end{array}$} \\
\hline Mathiesen & Pernille & & \\
\hline Mathisen & Gro & The Norwegian Scientific Committee for Food Safety & Norway \\
\hline Mattisson & Irene & Swedish National Food Agency & Sweden \\
\hline Meltzer & Helle Margrete & Norwegian Institute of Public Health & Norway \\
\hline Nurk & Eha & National Institute for Health Development & Estonia \\
\hline Nälsén & Cecilia & National Food Agency & Sweden \\
\hline Odland & Jon $\varnothing$ yvind & Dept. for Public Health, the Arctic University of Norway & Norway \\
\hline Olsen & Monica & Swedish National Food Agency & Sweden \\
\hline Sand & Salomon & Swedish National Food Agency & Sweden \\
\hline Segerbäck & Dan & Karolinska Institutet & Sweden \\
\hline Seidel & Albrecht & $\begin{array}{l}\text { Biochemical Institute for Environmental Carcinogens, Prof. Dr. } \\
\text { Gernot Grimmer-Foundation }\end{array}$ & Germany \\
\hline Steen & Merethe & Norwegian Food Safety Authority & Norway \\
\hline Thomsen & Cathrine & Norwegian Institute of Public Health & Norway \\
\hline Törnqvist & Margareta & Inst. for Environmental Chemistry, Stockholm University & Sweden \\
\hline Vare & Daniel & MBW, Stockholm University & Sweden \\
\hline Warholm & Margareta & Swedish Chemicals Agency & Sweden \\
\hline Vestergren & Robin & Norwegian Institute for air Research (NILU) & Norway \\
\hline Westin & Elin & The Public Health Agency of Sweden & Sweden \\
\hline Vikström & Anna & Formas & Sweden \\
\hline Åkesson & Agneta & IMM, Karolinska Institutet & Sweden \\
\hline Yome & Julie & Monitoring \& Surveillance Coordination, Health Canada & Canada \\
\hline
\end{tabular}




\section{Ved Stranden 18}

DK-1061 Copenhagen K

www.norden.org

\section{Human biomonitoring and policy making}

This report is based on the seminar "Human biomonitoring (HBM) as a tool in policy making towards consumer safety" directed towards professionals involved in HBM programs, legislators and other policy-makers, risk assessors as well as researchers from universities and other higher educational institutions. It was organized by the Swedish National Food Agency in collaboration with the Norwegian Food Safety Authority, the Norwegian Institute of Public Health, the University of Iceland, and Karolinska Institute, Sweden. Experts from Europe, USA, and Canada within the field of HBM participated. It was agreed that HBM provides a powerful tool in policy making towards consumer safety. It was also concluded that there is interest to develop the Nordic collaborative efforts within the area of HBM and that there would, unquestionably, be benefits from this in terms of harmonization.

TemaNord 2015:571

ISBN 978-92-893-4332-9 (PRINT)

ISBN 978-92-893-4334-3 (PDF)

ISBN 978-92-893-4333-6 (EPUB)

ISSN 0908-6692 